\title{
Indian Ocean tripole mode and its associated atmospheric and oceanic processes
}

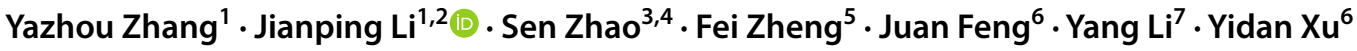

Received: 12 December 2019 / Accepted: 11 June 2020 / Published online: 16 June 2020

(c) The Author(s) 2020

\begin{abstract}
Differing from the Indian Ocean dipole (IOD) that has sea surface temperature anomalies (SSTAs) of opposing signs over the tropical southeastern and western Indian Ocean, a tripole pattern, characterized by positive (negative) SSTAs over the tropical central (southeastern and western) Indian Ocean, is observed and named the Indian Ocean tripole (IOT). This study proposes the concept of the IOT and further investigates the associated atmospheric and oceanic processes. Using empirical orthogonal function (EOF) analysis, the IOT (IOD) is represented by the third (second) leading mode of the monthly SSTAs in the tropical Indian Ocean, explaining about 8.2\% (10.3\%) of the total variance. The IOT peaks in boreal summer, while the IOD has its mature phase in boreal fall. The spatio-temporal differences, together with the significant separation of these two EOF patterns, illustrate that the IOT is independent of the IOD. Heat budget diagnoses indicate that the anomalous temperature over the southeastern and western Indian Ocean is mainly generated by the net heat flux during April-May and by the total ocean advection in June-August. In contrast, the anomalous temperature is mainly driven by the advection of the mean temperature by the anomalous current in April and the residual term in May-June over the central Indian Ocean, which is replaced by advection of the anomalous temperature by the mean zonal current in July.
\end{abstract}

Keywords Indian Ocean tripole (IOT) $\cdot$ Atmospheric and oceanic processes $\cdot$ Heat budget

\section{Introduction}

Changes in many extreme weather and climate events have been observed since the mid-20th century. For instance, the record-breaking heat wave of 1994 that occurred in East Asia and the catastrophic rainfall of 1961 in tropical eastern Africa resulted in severe economic and societal losses. These two extreme climatic events were both closely associated with sea surface temperature (SST) anomalies (SSTAs)

Jianping Li

ljp@ouc.edu.cn

1 Frontiers Science Center for Deep Ocean Multispheres and Earth System (FDOMES)/Key Laboratory of Physical Oceanography/Institute for Advanced Ocean Studies, Ocean University of China, Qingdao 266100, China

2 Laboratory for Ocean Dynamics and Climate, Pilot Qingdao National Laboratory for Marine Science and Technology, Qingdao 266237, China

3 CIC-FEMD/ILCEC, Key Laboratory of Meteorological Disaster of Ministry of Education, and College of Atmospheric Science, Nanjing University of Information Science and Technology, Nanjing, China over the tropical Indian Ocean rather than over the tropical Pacific Ocean (Saji et al. 1999; Guan and Yamagata 2003), leading to increasing interest in the tropical Indian Ocean during recent decades. Therefore, it is of great importance to understand tropical Indian Ocean climate variability.

Using empirical orthogonal function (EOF) analysis, Saji et al. (1999) identified the second leading mode of the SSTAs over the tropical Indian Ocean as the Indian Ocean Dipole (IOD), characterized by negative (positive) SSTAs

4 Department of Atmospheric Sciences, University of Hawaii at Mānoa, Honolulu, HI, USA

5 State Key Laboratory of Numerical Modeling for Atmospheric Sciences and Geophysical Fluid Dynamics, Institute of Atmospheric Physics, Chinese Academy of Sciences, Beijing 100029, China

6 College of Global Change and Earth System Science (GCESS), Beijing Normal University, Beijing 100875, China

7 College of Atmospheric Science, Plateau Atmosphere and Environment Key Laboratory of Sichuan Province, Chengdu University of Information Technology, Chengdu 610225, China 
over the tropical southeastern (western) Indian Ocean (Fig. 1a); this mode accounts for about $10.3 \%$ of the total variance of the tropical Indian Ocean SSTAs. Subsequently, many studies using observations and models have investigated the IOD in terms of its trigger mechanism (Annamalai et al. 2003; Fischer et al. 2005; Drbohlav et al. 2007; Huang and Shukla 2007a, b; Sun et al. 2015), seasonal evolution (Saji et al. 1999; Hong et al. 2008; Schott et al. 2009), impact factor (Lau and Nath 2004; Song et al. 2007; Tozuka et al. 2007; Krishnan and Swapna 2009; Stuecker et al. 2017; Zhang et al. 2018), prediction skill (Kug et al. 2004; Luo et al. 2007, 2008; Shi et al. 2011; Zhao et al. 2019), and

(a) EOF2 (10.3\%)

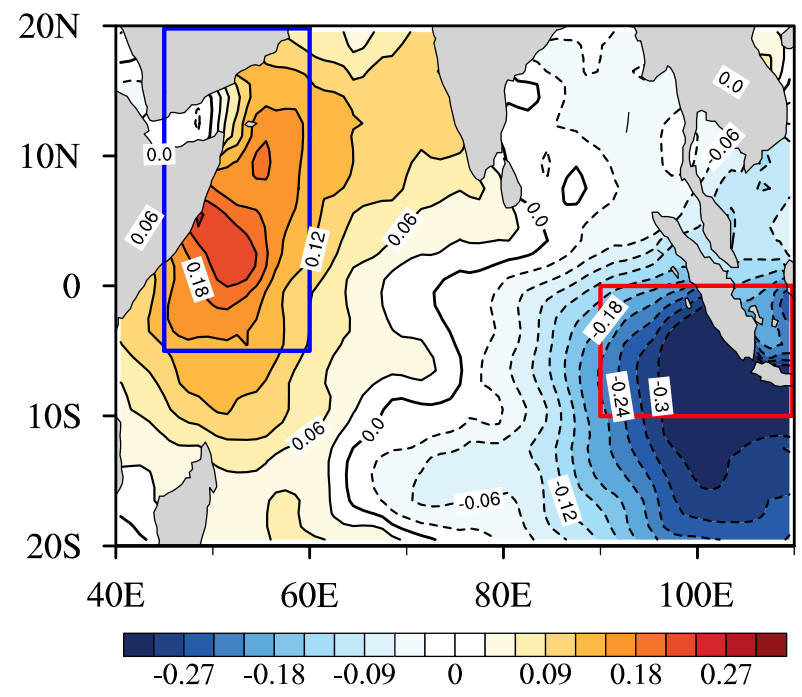

(c) EOF3 (8.2\%)

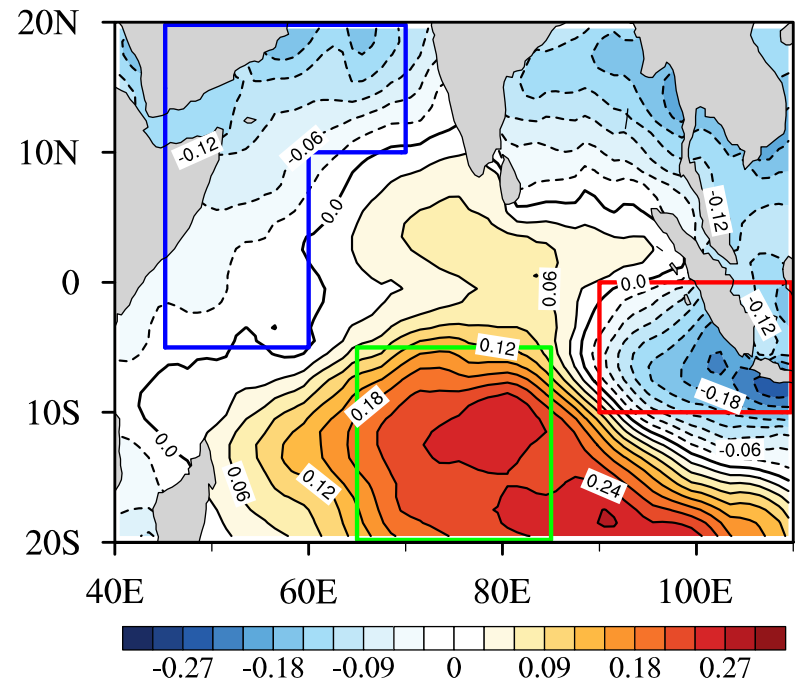

Fig. 1 a Spatial pattern of the second leading EOF (EOF2) mode of the monthly SSTAs over the tropical Indian Ocean. b Spatial pattern of the SSTAs $\left({ }^{\circ} \mathrm{C}\right)$ in the tropical Indian Ocean during August in 1994. c Same as a, but for the third leading EOF mode (EOF3). d The explained variances of the four leading modes using North's test. The energetics study (Wang et al. 2019). Its possible influences have also been investigated (Ashok et al. 2001; Li and $\mathrm{Mu}$ 2001; Guan and Yamagata 2003; Saji and Yamagata 2003; Yuan et al. 2008; Cai et al. 2009; Ding et al. 2010; Li et al. 2011a, b; Nuncio and Yuan 2015).

However, some studies have found differences in the seasonal evolution of IOD events (e.g., Rao and Yamagata 2004, Rao et al. 2009; Du et al. 2013). More recently, Endo and Tozuka (2016) compared the spatial patterns of SSTAs over the tropical Indian Ocean in the mature phase of the 1994 and 1997 IOD events (both are generally considered as representative positive events). In contrast to the

(b) 1994 August

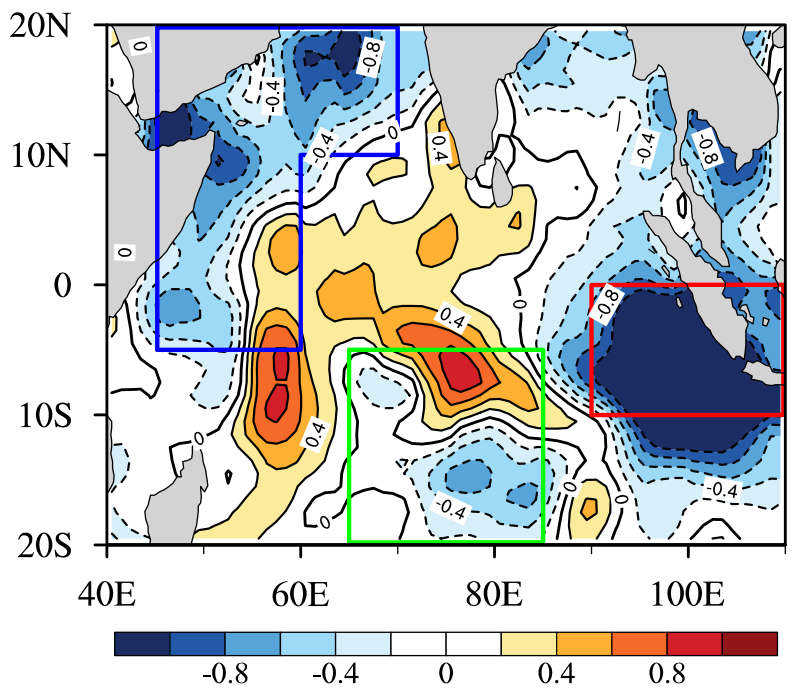

(d) North's test

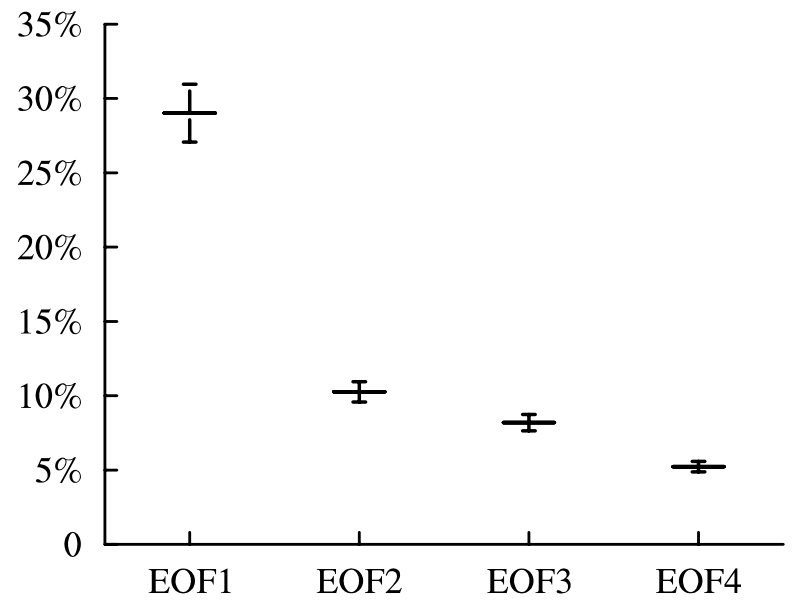

blue boxes in $\mathbf{a}$ and $\mathbf{b}-\mathbf{c}$ denote western $\left(45^{\circ}-60^{\circ} \mathrm{E}, 5^{\circ} \mathrm{S}-20^{\circ} \mathrm{N}\right)$ and $\left(45^{\circ}-60^{\circ} \mathrm{E}, 5^{\circ} \mathrm{S}-20^{\circ} \mathrm{N}\right.$ and $\left.60^{\circ}-70^{\circ} \mathrm{E}, 10^{\circ}-20^{\circ} \mathrm{N}\right)$ Indian Ocean, respectively. The red and green boxes in $\mathbf{a}-\mathbf{c}$ indicate the southeastern $\left(90^{\circ}-110^{\circ} \mathrm{E}, 0^{\circ}-10^{\circ} \mathrm{S}\right)$ and central $\left(65^{\circ}-85^{\circ} \mathrm{E}, 5^{\circ}-20^{\circ} \mathrm{S}\right)$ Indian Ocean, respectively 
IOD event during August in 1997 that was accompanied by negative (positive) SSTAs over the southeastern (western) Indian Ocean (Webster et al. 1999; Murtugudde et al. 2000), the tropical Indian Ocean SSTAs during August in 1994 showed a peculiar zonal tripole pattern (Fig. 1b): the tropical central Indian Ocean was warmer than normal, but it was flanked by colder SSTAs to its east and west.

Referring to the definition of the two types of El Niño-Southern Oscillation (ENSO) in the Pacific Ocean (Ashok et al. 2007), Endo and Tozuka (2016) also divided the IOD events into two types: the canonical IOD and IOD Modoki, which were separated by using the differences in the SSTAs area-averaged over the tropical western $\left(40^{\circ}-55^{\circ} \mathrm{E}, 10^{\circ} \mathrm{S}-15^{\circ} \mathrm{N}\right)$, central $\left(65^{\circ}-85^{\circ} \mathrm{E}, 15^{\circ} \mathrm{S}-0^{\circ}\right)$, and southeastern $\left(90^{\circ}-110^{\circ} \mathrm{E}, 0^{\circ}-10^{\circ} \mathrm{S}\right)$ Indian Ocean. The classification of the two types of IOD events is introduced as follows. They first defined a positive IOD event as the difference in SSTAs area-averaged over the central and southeastern tropical Indian Ocean exceeding one standard deviation. An IOD Modoki event is then identified when the difference in area-averaged SSTAs over the central and western tropical Indian Ocean is positive and its absolute value is greater than one standard deviation for at least two consecutive months between July and December. The other IOD events are referred to as canonical IOD events. The remarkable differences in the anomalous Walker circulation between these two types of the IOD are further investigated in Tozuka et al. (2016).

However, it is remarkable that this tripole pattern of the SSTAs in 1994 is similar to the third leading mode (EOF3) of Indian Ocean SSTAs, explaining about $8.2 \%$ of the total variance of the tropical Indian Ocean SSTAs (Fig. 1c). Furthermore, the variances explained by the EOF3 pattern are well separated from those explained by the EOF2, according to North's test (Fig. 1d; North et al. 1982). It is reasonable to hypothesize that this tripole pattern is a unique phenomenon independent of the IOD. Therefore, identifying and depicting this unique tripole pattern with an appropriate definition is the main motivation of this paper.

The remainder of this paper is organized as follows. The datasets and methods are briefly listed in Sect. 2. Section 3 introduces the definition of this unique tripole pattern, hereafter referred to as the Indian Ocean tripole (IOT), and then presents the differences between the IOT and IOD based on correlation and composite analyses. We examine atmospheric and oceanic processes associated with the IOT by utilizing the heat budget equation in Sect. 4, and the discussion and summary are given in Sect. 5 .

\section{Data and methodology}

\subsection{Data}

The monthly mean zonal and meridional wind at $10 \mathrm{~m}$ for the period $1982-2017$ on a $2.5^{\circ} \times 2.5^{\circ}$ grid are derived from the National Centers for Environmental Prediction reanalysis-2 (NCEP2) dataset, which is provided by the NOAA/OAR/ESRL Physical Sciences Division (PSD), Boulder, Colorado, from their website at https://www. esrl.noaa.gov/psd/data/gridded/data.ncep.reanalysis $2 . h t m l$ (Kanamitsu et al. 2002). The Optimum Interpolation SST (OISST) analysis dataset on a $0.25^{\circ} \times 0.25^{\circ}$ grid for 1982-2017 is used in this study because of its better and more reliable data quality based on both in situ and satellite data (Reynolds et al. 2002). To validate the robustness of our results, we have also used another two datasets available for the same period with a horizontal resolution of $2^{\circ} \times 2^{\circ}$ : the improved Extended Reconstructed SST version 5 (ERSST v5; Huang et al. 2017) and the Hadley Centre Global Sea Ice and SST (HadISST; Rayner et al. 2003) datasets.

To better understand the atmospheric and oceanic processes of IOT evolution, the heat budget is calculated. The ocean subsurface temperature and the three-dimensional ocean circulation during 1979-2010 from the Simple Ocean Data Assimilation (SODA 2.2.4) system are used to describe the oceanic processes (Carton and Giese 2008). The atmospheric processes are depicted by the net heat surface flux from the Objectively Analyzed air-sea Fluxes version 3 (OAflux) data products for 1984-2009, which are available at ftp://ftp.whoi.edu/pub/science/oaflu x/data_v3 (Yu et al. 2008). Before analyzing our results, the linear trend and the long-term mean climatology have been removed from each dataset.

In addition, the Indian Ocean basin-wide mode (IOBM) index is calculated from the SSTAs area-averaged over $40^{\circ}-110^{\circ} \mathrm{E}, 20^{\circ} \mathrm{S}-20^{\circ} \mathrm{N}$, and the IOD mode index (DMI) is defined as the difference in SSTAs between the tropical western Indian Ocean $\left(45^{\circ}-60^{\circ} \mathrm{E}, 5^{\circ} \mathrm{S}-20^{\circ} \mathrm{N}\right)$ and the southeastern Indian Ocean $\left(90^{\circ}-110^{\circ} \mathrm{E}, 10^{\circ} \mathrm{S}-0^{\circ}\right)$. Although the location of the western Indian Ocean region is shifted northwestward slightly compared with the region used by Saji et al. (1999), the correlation coefficient between them still exceeds 0.95 (beyond the $99 \%$ confidence level), indicating that this index can also represent the IOD variability. The subtropical IOD (SIOD) mode index (SDMI) is like the DMI, but for the western $\left(55^{\circ}-65^{\circ} \mathrm{E}, 27^{\circ}-37^{\circ} \mathrm{S}\right)$ and eastern $\left(90^{\circ}-100^{\circ} \mathrm{E}, 18^{\circ}-28^{\circ}\right.$ S) subtropical Indian Ocean (Behera and Yamagata 2001). The canonical ENSO is represented here by the Niño3 index that is calculated from the SSTAs area-averaged over 
the equatorial central-eastern Pacific $\left(150^{\circ} \mathrm{W}-90^{\circ} \mathrm{W}, 5^{\circ}\right.$ $\mathrm{S}-5^{\circ} \mathrm{N}$ ). The ENSO Modoki index (EMI) is defined in terms of the differences in the SSTAs between the cen$\operatorname{tral}\left(165^{\circ} \mathrm{E}-140^{\circ} \mathrm{W}, 10^{\circ} \mathrm{S}-10^{\circ} \mathrm{N}\right)$ tropical Pacific Ocean and the eastern $\left(110^{\circ} \mathrm{W}-70^{\circ} \mathrm{W}, 15^{\circ} \mathrm{S}-5^{\circ} \mathrm{N}\right)$ and western $\left(125^{\circ} \mathrm{E}-145^{\circ} \mathrm{E}, 10^{\circ} \mathrm{S}-20^{\circ} \mathrm{N}\right)$ tropical Pacific Ocean (Ashok et al. 2007).

\subsection{Methodology}

Firstly, the IOD and IOT signals can be clearly identified by EOF analysis, in which the principal components are divided by their standard deviation and the spatial EOF patterns are multiplied by the corresponding standard deviation (Ashok et al. 2007; Li et al. 2015). North's test is used to examine the separation between the two EOF modes (North et al. 1982). In order to explore the relations of the IOT and the IOD, SIOD, and two types of ENSO, we calculate the lead-lag correlations of the IOT with different modes; a two-tailed Student's $t$ test using the effective number of degrees of freedom $\left(N_{e f f}\right)$ is used to test significance. For the variables $X$ and $Y$, the significance of their correlation can be calculated using the following approximation (e.g. Bretherton et al. 1999; Li et al. 2013):

$\frac{1}{N_{e f f}} \approx \frac{1}{N}+\frac{2}{N} \sum_{i=1}^{N} \frac{N-i}{N} \rho_{X X}(i) \rho_{Y Y}(i)$

where $N$ is the total number of samples in the time series; $\rho_{X X}(i)$ and $\rho_{Y Y}(i)$ denote the autocorrelations of the two time series $X$ and $Y$ at time lag $i$, respectively.

In light of previous studies (Kug et al. 2009; Ren and Jin 2013; Li et al. 2015), the heat budget is applied to determine the contributions of the atmospheric and oceanic processes to the IOT. These contributions can be calculated from the following heat budget equation: where $Q_{n e t}^{\prime}, C_{p}, \rho$, and $H$ represent the net surface heat flux, the specific heat of sea water, the density of sea water, and the climatological mixed layer depth $(H=40 \mathrm{~m}$, Kara et al. 2003), respectively.

\section{Indian Ocean Tripole (IOT)}

\subsection{Definition of the IOT}

As shown in Fig. 1a, the EOF2 pattern captures the wellknown IOD features, characterized by negative (positive) SSTAs over the tropical southeastern (western) Indian Ocean. However, the EOF3 is characterized by positive (negative) SSTAs over the tropical central (southeastern and western) Indian Ocean, showing a remarkable tripole pattern (Fig. 1c). Although the variances explained separately by EOF2 and EOF3 are very close, with values of $10.3 \%$ and $8.2 \%$ (Fig. 1a, c), these two EOF modes are separated according to North's test (Fig. 1d; North et al. 1982). Similar EOF results can be also obtained by using the HadISST and ERSSTv5 datasets, except for slight differences in the variance explained by the EOF2 and EOF3 (not shown), further demonstrating the robustness of these results. This suggests that these two patterns represent different modes of the climate variability over the tropical Indian Ocean. Due to the evident difference from the well-known IOD pattern, we refer to the SSTAs pattern in 1994 and the EOF3 pattern (Fig. 1b, c), namely, warming in the central Indian Ocean flanked by colder SSTAs to its west and east, as the IOT (Indian Ocean tripole).

The time series of normalized principal component (PC) of EOF3 is displayed in Fig. 2. The zero-lag correlation between the PC 3 and PC2 is zero by definition, while the

$$
\frac{\partial T^{\prime}}{\partial t}=\underbrace{-\bar{u} \frac{\partial T^{\prime}}{\partial x}-u^{\prime} \frac{\partial \bar{T}}{\partial x}-u^{\prime} \frac{\partial T^{\prime}}{\partial x}}_{\text {Total } \mathrm{U} \text { advection }}+\underbrace{-\bar{v} \frac{\partial T^{\prime}}{\partial y}-v^{\prime} \frac{\partial \bar{T}}{\partial y}-v^{\prime} \frac{\partial T^{\prime}}{\partial y}}_{\text {Total } \mathrm{V} \text { advection }}+\underbrace{-\bar{w} \frac{\partial T^{\prime}}{\partial z}-w^{\prime} \frac{\partial \bar{T}}{\partial z}-w^{\prime} \frac{\partial T^{\prime}}{\partial z}}_{\text {Total } \mathrm{W} \text { advection }}+Q^{\prime}+R,
$$

where overbars and primes present the monthly mean climatology and deviations from climatology, respectively. The variables $u(\mathrm{U}), v(\mathrm{~V}), w(\mathrm{~W}), T, Q^{\prime}$, and $R$ denote the zonal current, meridional current, vertical current, ocean temperature, thermal forcing, and residual terms, respectively. Notably, $R$ is neglected in this study and the $Q^{\prime}$ in the oceanic mixed layer can be derived from the following expression:

$Q^{\prime}=\frac{Q_{n e t}^{\prime}}{\rho C_{p} H}$,
PC3 has a maximum but insignificant correlation of 0.21 with the PC2 when the PC2 leads PC 3 by about 3 months (not shown), suggesting that the maximum variances of each PC explained by the other are less than 5\%. On the basis of the EOF3 pattern shown in Fig. 1c and the PC3 time series presented in Fig. 2, an IOT mode index (TMI) is devised and defined as follows:

$\mathrm{TMI}=[\text { SSTAs }]_{\mathrm{C}}^{*}-\frac{1}{2}\left([\text { SSTAs }]_{\mathrm{E}}^{*}+[\text { SSTAs }]_{\mathrm{W}}^{*}\right)$,

where the square brackets in Eq. (3) denote the area-averaged SSTAs over three regions ("C", "E" and "W") in the 

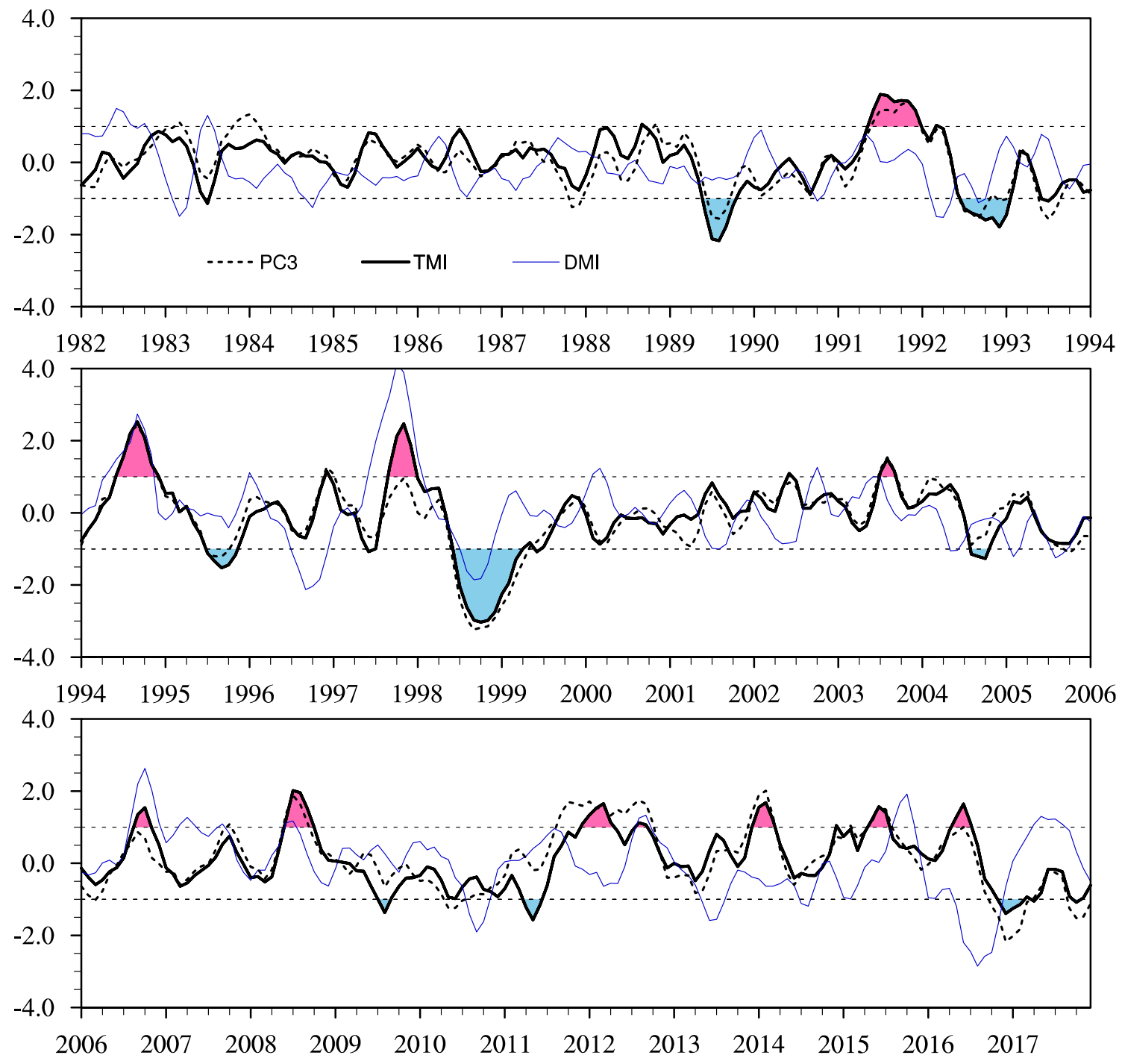

Fig. 2 Time series of the normalized PC3 (black dashed line), TMI (black solid line), and DMI (blue solid line). The dashed lines denote 1 (- 1) standard deviation, and the pink (light blue) shading indicates values above (below) $1(-1)$ standard deviation of the TMI

tropical Indian Ocean. "C", "E" and "W" represent the central $\left(65^{\circ}-85^{\circ} \mathrm{E}, 5^{\circ}-20^{\circ} \mathrm{S}\right)$, southeastern $\left(90^{\circ}-110^{\circ} \mathrm{E}, 10^{\circ}\right.$ $\left.\mathrm{S}-0^{\circ}\right)$, and western $\left(45^{\circ}-60^{\circ} \mathrm{E}, 5^{\circ} \mathrm{S}-20^{\circ} \mathrm{N}\right.$ and $60^{\circ}-70^{\circ} \mathrm{E}$, $10^{\circ}-20^{\circ} \mathrm{N}$ ) regions of the tropical Indian Ocean (Fig. 1c), respectively. To exclude interference of the IOD, the asterisk indicates that the EOF2 signals have been removed from the SSTAs before calculating the TMI. It is noted that the EOF2 signals are not excluded from other anomaly fields in the following analyses. Figure 2 displays the time series of the normalized TMI, showing a significant interannual variability. The correlation between the TMI and PC3 is very high (0.9), demonstrating that the TMI introduced here is an appropriate index to represent the IOT events in the tropical Indian Ocean.

\subsection{Differences between the IOT and the IOD}

Similar to the insignificant correlation between the PC2 and PC3, the correlation between the TMI and DMI is also insignificant with a value of 0.2 (Table 1), implying that substantial percentages of the variances explained by the IOT (IOD) are not explained by the IOD (IOT) during the study period (1982-2017). Moreover, both the SDMI and

Table 1 Correlations between pairs of indices during 1982-2017

\begin{tabular}{lllllc}
\hline Correlations & DMI & TMI & Niño3 & EMI & SDMI \\
\hline DMI & - & 0.2 & $0.27^{*}$ & 0.13 & 0.05 \\
TMI & 0.2 & - & 0.21 & $0.24^{*}$ & $-0.54^{*}$
\end{tabular}

The asterisk indicates significance at the $99 \%$ confidence level 
EMI are significantly correlated with the TMI with values of -0.54 and 0.24 , respectively, much larger than the insignificant correlation ( 0.21 ; Table 1$)$ between the TMI and the Niño3 index. However, the DMI is significantly correlated only with the Niño3 index (0.27), a much stronger correlation than with the EMI and SDMI (Table 1). These results indicate that the IOT (IOD) is more closely linked with the SIOD and ENSO Modoki (canonical ENSO) than with the canonical ENSO (SIOD and ENSO Modoki).

The above preliminary correlation analyses indicate that the IOT may differ from the IOD in its relation to other modes. As presented in Fig. 2, we can also observe the remarkable differences in seasonal evolution between the IOT and IOD. The IOT generally reaches a mature phase in boreal summer (June-July-August, JJA), leading the IOD that peaks in September-October-November (SON) by about one season. The similar results can be also obtained even though the TMI is calculated based on the raw SSTAs (not shown). To further illustrate these results, the IOT and IOD years are detected. Due to the mature phase of the IOD during SON, the IOD years are identified with the absolute amplitude of the DMI exceeding 1 standard deviation threshold during SON. In order to objectively classify the IOD and IOT years, the two conditions are applied to select the IOT years: (1) the absolute amplitude of the TMI exceeding 1 standard deviation threshold during JJA; (2) the east and west poles having same polarity and opposite to the central pole. On the basis of the above criteria, 9 IOT (7 IOD) years are identified, which is shown in Table 2. In contrast to the IOD years selected by Endo and Tozuka (2016), the more IOD events are detected in this study, which is more in tune with the previous results (Australian Bureau of Meteorology, available at http://www.bom.gov.au/climate/iod/\#tabs=Posit ive-IOD-impacts). Although the same 4 positive IOT (IOD Modoki) events are both classified (Endo and Tozuka 2016), there exist the evident differences in selecting the negative phases. Beside the common 1992 and 1998 years, the east and west poles during JJA have the same polarity and are opposite to the central pole in 1993, 1995 and 2009 years (not shown). Thus, these three years are also defined as the IOT events (Table 2). The aforementioned differences may be due to the different physical meanings between the IOT and IOD events.

Table 2 Phases and classification of the IOT and IOD years during 1982-2017

\begin{tabular}{lll}
\hline Classification & IOT & IOD \\
\hline Positive phase & $1991,1994,2003$, & $1997,2002,2006,2015$ \\
& 2008 & \\
Negative phase & $1992,1993,1995$, & $1996,2010,2016$ \\
& 1998,2009 & \\
\hline
\end{tabular}

Using the selected IOT and IOD years (Table 2), we present a composite analysis based on the positive and negative phases of the IOT and IOD years that we defined as occurring during our study period (1982-2017). Figure 3a shows the composites of the monthly evolution of TMI and DMI. The IOT events start to develop from May, peak in August and decay gradually over the rest of year (Fig. 3a). In contrast, the IOD events develop in July and become mature in October, lagging the IOT by about 3 months (Fig. 3a). At the same time, the IOT events have much greater magnitude during JJA than the IOD events, while the situation is reversed during SON (Fig. 3a). Similar results can also be derived from the ERSST v5 and HadISST datasets, demonstrating that the IOT is clearly different from the IOD (Fig. 3e, i).

On the other hand, given that two of the regions defining the IOT and IOD overlap (the southeastern and western tropical Indian Ocean), it is necessary to discuss further the differences in these study regions. Similar to the TMI, the negative SSTAs over the southeastern Indian Ocean develop from May, peak in August and decay slowly over the rest of the year during IOT events (Fig. 3b). However, the negative SSTAs over the southeastern Indian Ocean associated with the IOD events start to develop in July and mature in October, lagging the IOT by about 3 months (Fig. 3b). Moreover, the intensity of negative SSTAs over the southeastern Indian Ocean for the IOT events is much stronger than that for IOD events during JJA, while the situation is reversed during SON (Fig. 3b). The SSTAs over the central Indian Ocean have the opposite sign to those over the southeastern Indian Ocean for both IOT and IOD events. However, the SSTAs over the central Indian Ocean peak in JJA (SON) during the IOT (IOD) events (Fig. 3c). The major differences between the IOT and the IOD exist over the western Indian Ocean. As for the IOD events during JJA, the SSTAs over the western Indian Ocean are opposite to those over the southeastern Indian Ocean (Fig. 3b-d). However, during IOT events, the anomalies over the western and southeastern Indian Ocean have the same polarity, opposite to those over the central Indian Ocean (Fig. 3b-d). Notably, although the SSTAs over the western Indian Ocean are of short duration during IOT events, they have similar amplitude to those over the central Indian Ocean, especially in July-August, suggesting that the central Indian Ocean SSTAs are as important as those of the western Indian Ocean (Fig. 3b-d). The similar results obtained from the ERSST v5 and HadISST datasets further demonstrate the robustness of these results (Fig. 3e-1).

Besides the SSTAs, the surface wind anomalies over the Indian Ocean also show remarkable differences between IOT and IOD events. Figure 4 displays composites of the monthly $10-\mathrm{m}$ surface zonal and meridional wind anomalies over the tropical Indian Ocean during IOT and IOD events. Similar to the SSTAs, the surface southeasterly wind anomalies over the southeastern Indian Ocean mature 
(a) OISST TMI \& DM

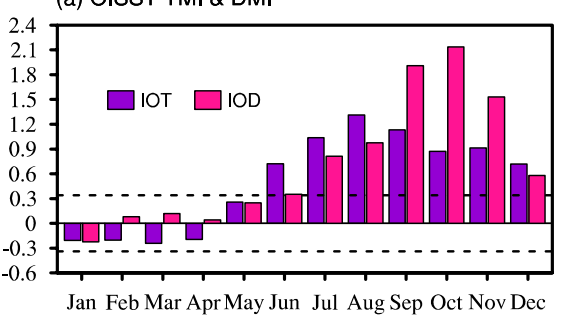

(b) OISST east Indian Ocean

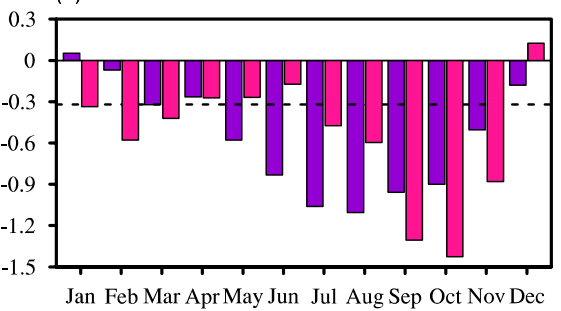

(c) OISST central Indian Ocean

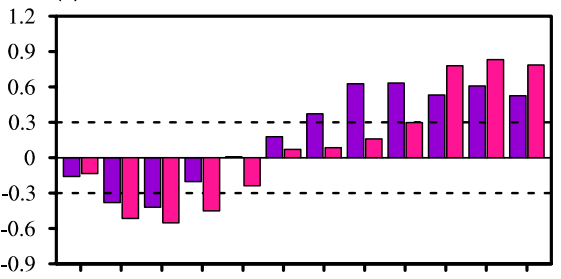

Jan Feb Mar Apr May Jun Jul Aug Sep Oct Nov Dec (d) OISST west Indian Ocean

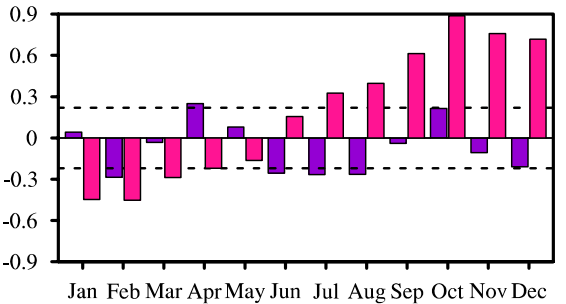

(e) ERSST TMI \& DMI

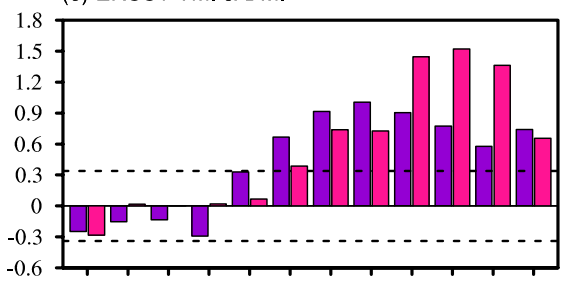

Jan Feb Mar Apr May Jun Jul Aug Sep Oct Nov Dec (f) ERSST east Indian Ocean

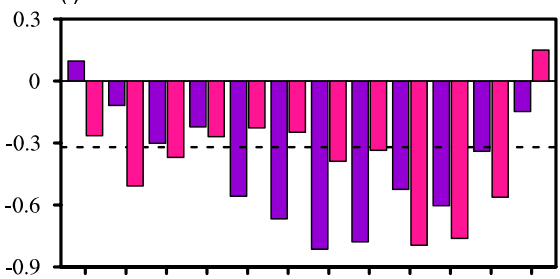

Jan Feb Mar Apr May Jun Jul Aug Sep Oct Nov Dec (g) ERSST central Indian Ocean

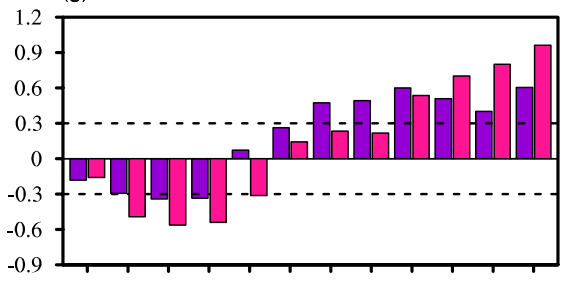

Jan Feb Mar Apr May Jun Jul Aug Sep Oct Nov Dec (h) ERSST west Indian Ocean

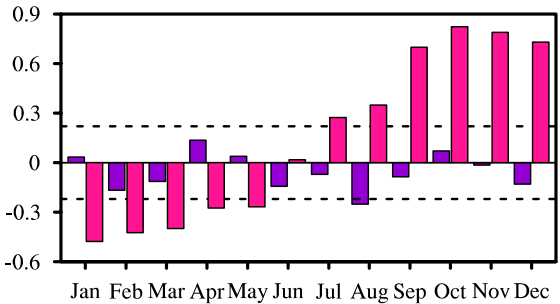

(i) HadISST TMI \& DMI

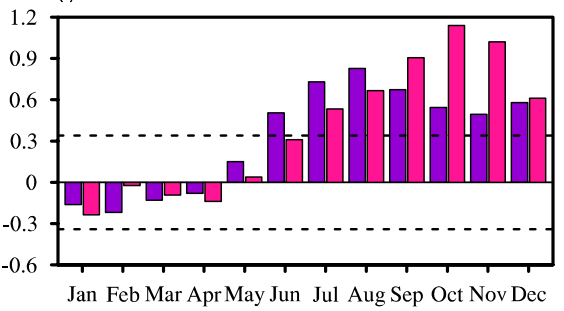

(j) HadISST east Indian Ocean

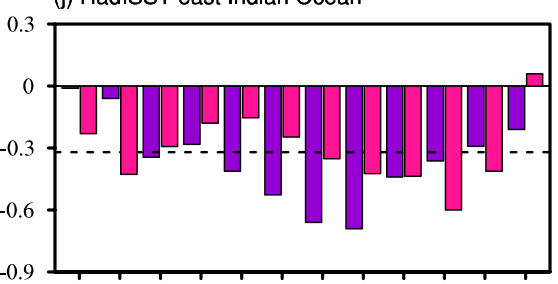

Jan Feb Mar Apr May Jun Jul Aug Sep Oct Nov Dec (k) HadISST central Indian Ocean

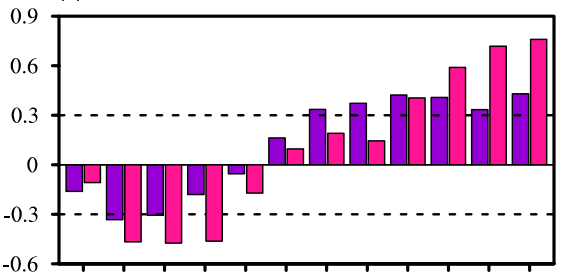

Jan Feb Mar Apr May Jun Jul Aug Sep Oct Nov Dec (I) HadISST west Indian Ocean

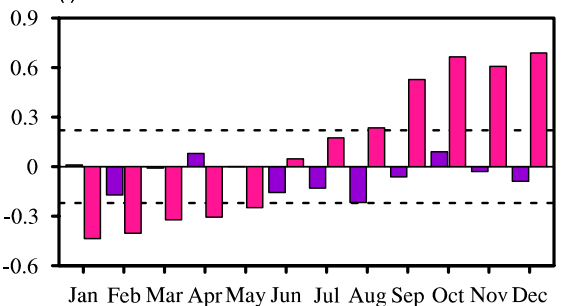

Fig. 3 Composite monthly evolution of $\mathbf{a}$ the TMI $\left({ }^{\circ} \mathrm{C}\right)$ and $\mathbf{b}-\mathbf{d}$ the SSTAs $\left({ }^{\circ} \mathrm{C}\right)$ over the b southeastern $\left(90^{\circ}-110^{\circ} \mathrm{E}, 0^{\circ}-10^{\circ} \mathrm{S}\right)$, c central $\left(65^{\circ}-85^{\circ} \mathrm{E}, 5^{\circ}-20^{\circ} \mathrm{S}\right)$, and d western $\left(45^{\circ}-60^{\circ} \mathrm{E}, 5^{\circ} \mathrm{S}-20^{\circ} \mathrm{N}\right.$ and $60^{\circ}-70^{\circ} \mathrm{E}, 10^{\circ}-20^{\circ} \mathrm{N}$ ) Indian Ocean for the IOT (dark violet bars)

from May to July during the IOT events, while the surface southeasterly wind anomalies related to the IOD events peak in SON (Fig. 4a, d). The equatorial easterly wind anomalies over the central Indian Ocean during IOT events are also earlier and stronger than those of IOD events from April to July, and then weaken in the following months, when the equatorial easterly wind anomalies during IOD events reach their peak (Fig. 4b). Unlike the northerly wind anomalies over the central Indian Ocean $\left(65^{\circ}-80^{\circ}\right.$ E, $15^{\circ} \mathrm{S}-0^{\circ}$ ) that peak in SON during IOD events, the northerly wind anomalies associated with the IOT events develop from May and persist up to November (Fig. 4e). In the western Indian Ocean, the seasonal evolution is clearly observed in the surface zonal wind anomalies (Fig. 4c), but is not evident in the meridional wind anomalies (Fig. 4f). More importantly, there are contrasting zonal and IOD (deep pink bars) events based on the OISST dataset. e-I Same as a-d, but for the ERSST v5 and HadISST datasets. Dashed lines denote $1(-1)$ standard deviation

wind anomalies over the western Indian Ocean between the IOT and IOD events (Fig. 4c).

Actually, the significant differences in the SSTAs between the IOT and IOD events are strongly related to the contrasting wind anomalies. The spatial composites of the monthly evolution of the SSTAs and 10-m surface wind anomalies from May to December during IOT and IOD events are shown in Fig. 5. In the IOT events, significant southeasterly anomalies over the southeastern Indian Ocean first appear in April-May (Fig. 4a, d), favoring cold SSTAs there in May (Fig. 5a). In contrast to the IOT events, the southeasterly wind anomalies over the southeastern Indian Ocean that also appear in May during the IOD events have weak amplitude (Fig. 4b, d), and are accompanied by weak cold SSTAs over the southeastern Indian Ocean (Fig. 5i). At the same time, a strong anticyclone induced by the southeasterly 
(a) Zonal wind $\left(90^{\circ}-110^{\circ} \mathrm{E}, 10^{\circ} \mathrm{S}-0^{\circ}\right)$

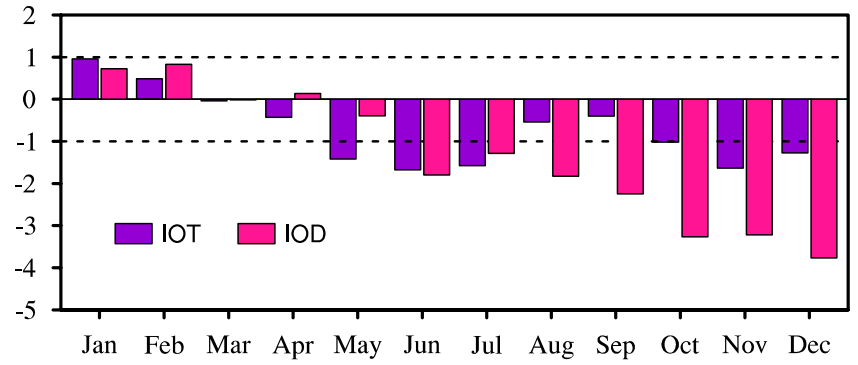

(b) Zonal wind $\left(70^{\circ}-90^{\circ} \mathrm{E}, 5^{\circ} \mathrm{S}-5^{\circ} \mathrm{N}\right)$

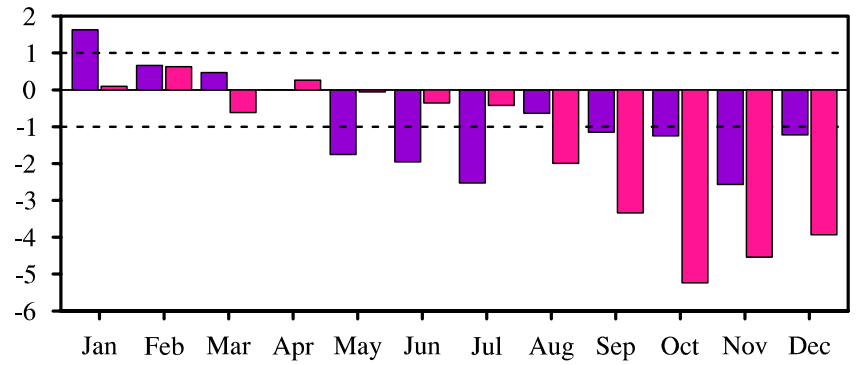

(c) Zonal wind $\left(45^{\circ}-60^{\circ} \mathrm{E}, 5^{\circ} \mathrm{S}-10^{\circ} \mathrm{N}\right)$

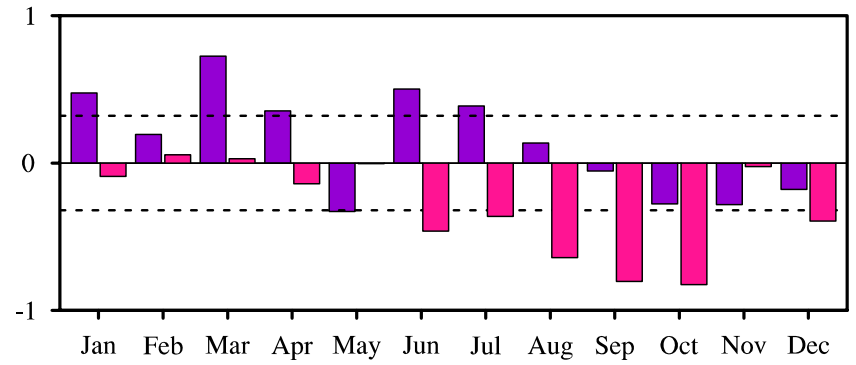

Fig. 4 Composites of the 10-m zonal wind anomalies $\left(\mathrm{m} \mathrm{s}^{-1}\right)$ over the southeastern $\left(90^{\circ}-110^{\circ} \mathrm{E}, 10^{\circ} \mathrm{S}-0^{\circ}\right)$, b central $\left(70^{\circ}-90^{\circ} \mathrm{E}, 5^{\circ} \mathrm{S}-5^{\circ}\right.$ $\mathrm{N})$, and $\mathbf{c}$ western $\left(45^{\circ}-60^{\circ} \mathrm{E}, 5^{\circ} \mathrm{S}-10^{\circ} \mathrm{N}\right)$ Indian Ocean for the IOT (dark violet bars) and IOD (deep pink bars) events. d-f same as a-c,

wind anomalies is established over the southeastern Indian Ocean in May during the IOT events, centered at $10^{\circ} \mathrm{S}, 100^{\circ}$ E (Fig. 5a), much stronger than that related to the IOD events (Fig. 5i). As a result, prominent northerly wind anomalies prevail on the west of this anticyclone during IOT events, bringing warmer sea water to the central-southern Indian Ocean, resulting in warmer SSTAs (Fig. 5a). However, there are cold SSTAs associated with the IOD events in May over the central-southern Indian Ocean because of the lack of evident northerly wind anomalies (Fig. 5i). In the western Indian Ocean, the amplitude of SSTAs of the IOT is comparable to that of the IOD in May due to the similar surface wind anomalies (Fig. 5a, i).

The cold SSTAs off Sumatra-Java induced by the enhanced southeasterly wind anomalies intensify in JJA for the IOT events (Figs. 4a, b, 5b-d). Meanwhile, the enhanced westerly wind anomalies over the western Indian Ocean prevail eastward along the equator (Fig. 4c, f), strengthening the (d) Meridional wind $\left(90^{\circ}-110^{\circ} \mathrm{E}, 10^{\circ} \mathrm{S}-0^{\circ}\right)$

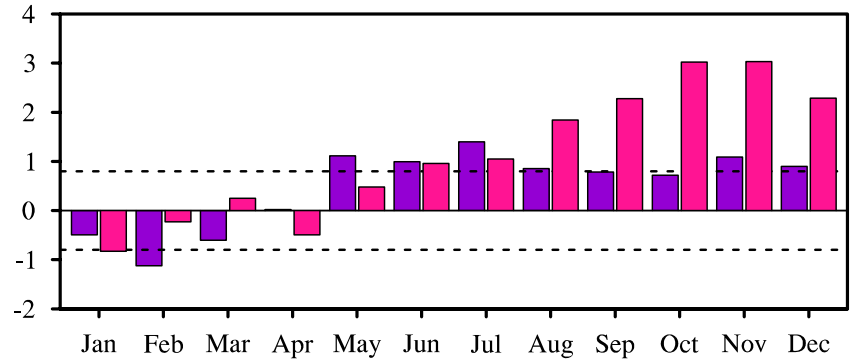

(e) Meridional wind $\left(65^{\circ}-80^{\circ} \mathrm{E}, 15^{\circ} \mathrm{S}-0^{\circ}\right)$

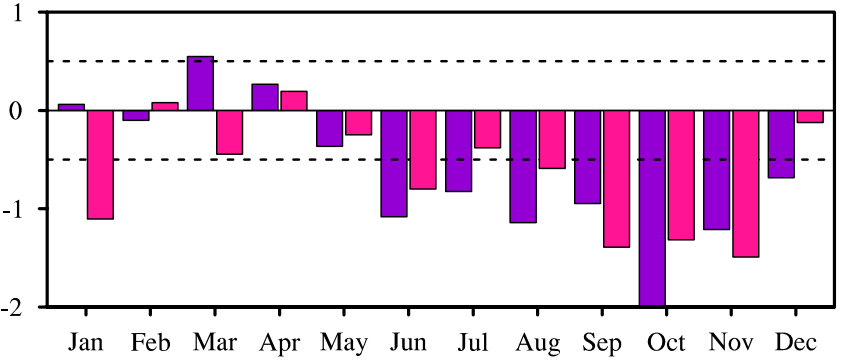

(f) Meridional wind $\left(45^{\circ}-60^{\circ} \mathrm{E}, 5^{\circ} \mathrm{S}-10^{\circ} \mathrm{N}\right)$

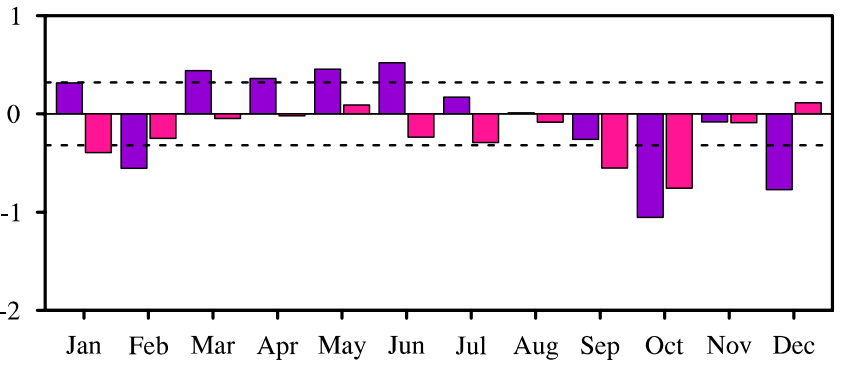

but for the meridional wind anomalies $\left(\mathrm{m} \mathrm{s}^{-1}\right)$ over the $\mathbf{d}$ southeastern $\left(90^{\circ}-110^{\circ} \mathrm{E}, 10^{\circ} \mathrm{S}-0^{\circ}\right)$, e central $\left(65^{\circ}-80^{\circ} \mathrm{E}, 15^{\circ} \mathrm{S}-0^{\circ}\right)$, and f western $\left(45^{\circ}-60^{\circ} \mathrm{E}, 5^{\circ} \mathrm{S}-10^{\circ} \mathrm{N}\right)$ Indian Ocean, respectively. Dashed lines denote $1(-1)$ standard deviation

cold SSTAs over there during this period (Fig. 5b-d). Consequently, the easterly wind anomalies from the southeastern Indian Ocean converge with the westerly wind anomalies from the western Indian Ocean in the equatorial central Indian Ocean, significantly reinforcing the northerly wind anomalies over the central Indian Ocean to the south of the equator (Fig. 4c) and consequently leading to warm SSTAs over the central-southern Indian Ocean (Fig. 5b-d). The significant warm SSTAs over the southern Indian Ocean, together with the significant cold SSTAs over the southeastern and western Indian Ocean, show a remarkable tripole pattern, suggesting the mature phase of the IOT during JJA (Fig. 5b-d). In contrast, during the IOD events, although the cold SSTAs over the southeastern Indian Ocean are also strengthened by the enhanced southeasterly wind anomalies in JJA (Figs. 4a, b, 5j-1), the enhanced southeasterly wind anomalies not only propagate to the western Indian Ocean along the equator but also intensify the anticyclone over the 
(a) May

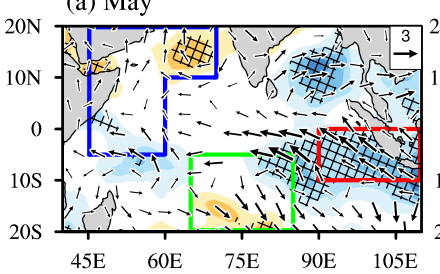

(e) Sep

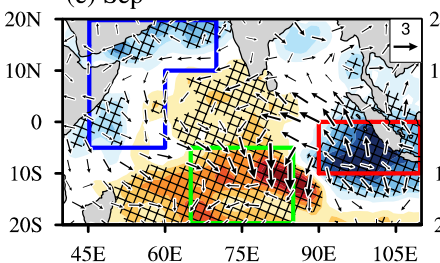

(i) May

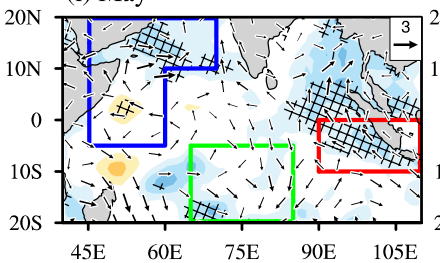

(m) Sep
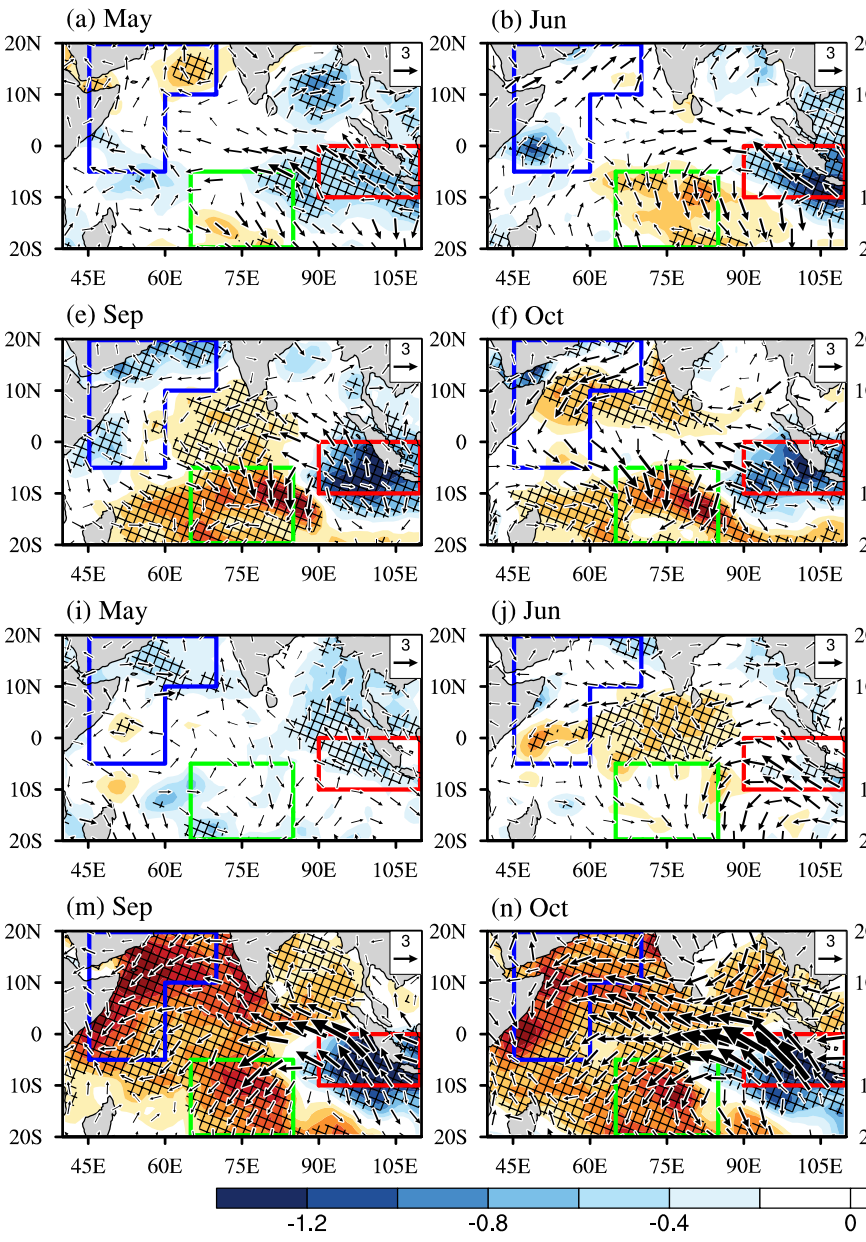

(f) Oct

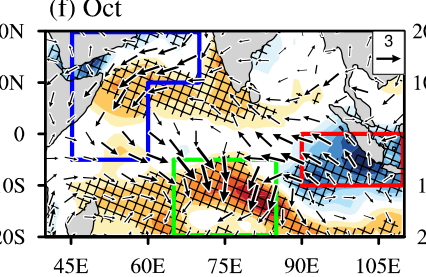

(j) Jun

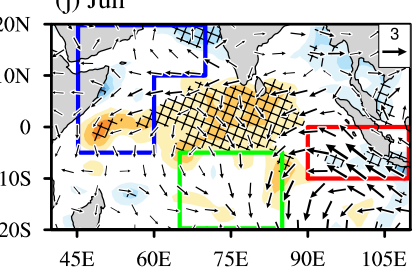

(n) Oct

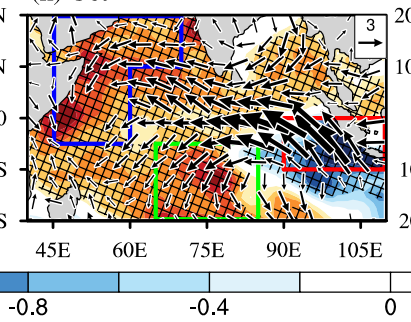

(c) Jul

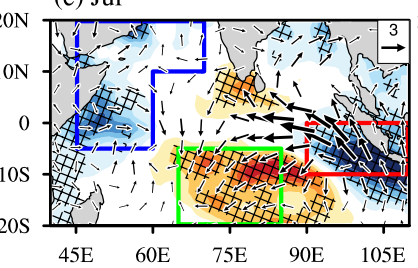

(g) Nov

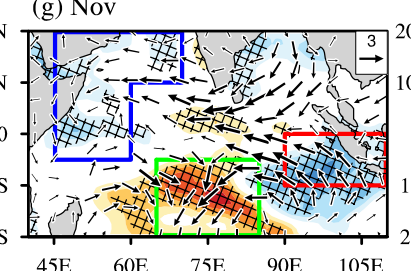

(k) Jul

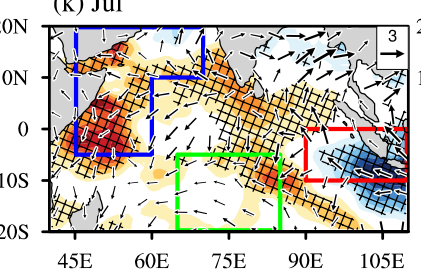

(o) Nov (d) Aug

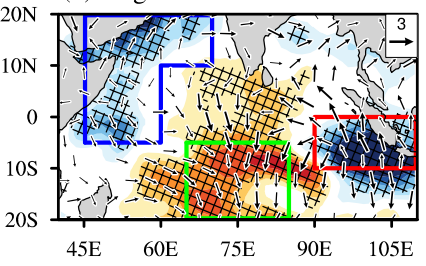

(h) Dec

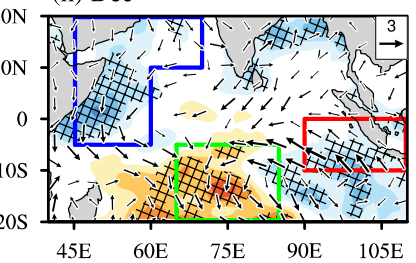

(1) Aug

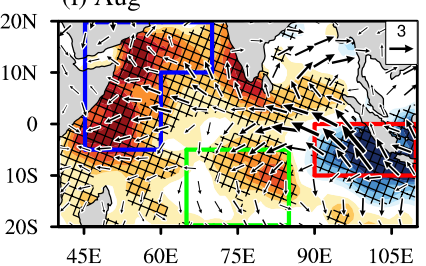

(p) Dec

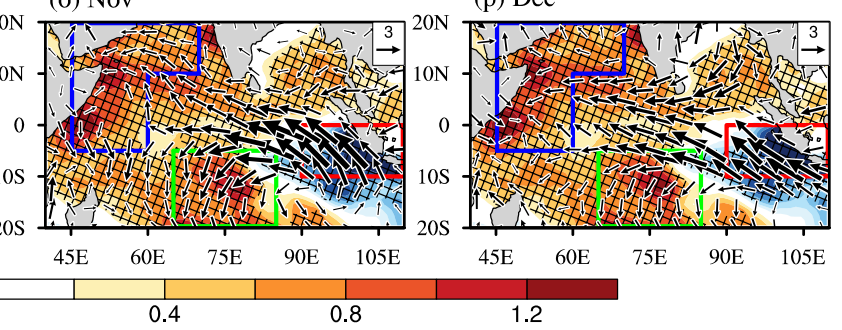

Fig. 5 Monthly evolution of composite SSTAs (shading, ${ }^{\circ} \mathrm{C}$ ) and $10-\mathrm{m}$ wind anomalies (arrows; $\mathrm{m} \mathrm{s}^{-1}$ ) over the tropical Indian Ocean from May to December for the IOT (a-h) and IOD (i-p) events. The red, green, and blue rectangles are the same as in Fig. 1b. Hatching indicates composites exceeding the $95 \%$ confidence level. Only wind vectors that are significant at the $95 \%$ confidence level are plotted southern Indian Ocean, further warming the SSTAs over the western and central-southern Indian Ocean (Fig. 5j-1). These changes indicate the development of the IOD event.

The reduction of the southeasterly wind anomalies off Sumatra-Java is accompanied by a weakened anticyclone over the southern Indian Ocean in September-December during the IOT events (Fig. 4a, b), resulting in the decay of the SSTAs over the southeastern and central-southern Indian Ocean (Fig. 5e-h). At the same time, the warm SSTAs over the central-northern Indian Ocean, forced by the enhanced easterly wind anomalies over the northern Indian Ocean, extend westward and accelerate the decay of the cold SSTAs over the western Indian Ocean in September-October (Fig. 5e-h). This indicates that the significant tripole pattern of the IOT events starts to decay rapidly in September-October, and weakens gradually in November-December, but still shows a weak tripole pattern (Fig. 5e-h). However, during IOD events, the southeasterly wind anomalies further strengthen and cover the whole Indian Ocean in SON, contributing to the peaking of the SSTAs over the southeastern, central-southern and western Indian Ocean (Fig. 5m-o). This indicates the mature phase of the IOD events in this period. The SSTAs over the southeastern and western Indian Ocean associated with the IOD events begin to decay due to the decreased easterly anomalies in December (Figs. 4b, $5 p)$. Overall, although two of the regions defining the IOT and IOD events overlap, the changes in the seasonal evolution of the SSTAs are clearly different due to the contrasting wind anomalies, proving that the IOT is quite distinct from the IOD.

In addition, we also found a clear difference on the interannual timescale between the IOT and IOD events. We therefore calculate the monthly correlations between the TMI and DMI over the period 1982-2017 (Fig. 6a). There are two periods of significant correlation: one is from February to April, and the other during SON. In general, the IOT and IOD have not yet developed in the first significant period, and the significant correlations between the IOT and 


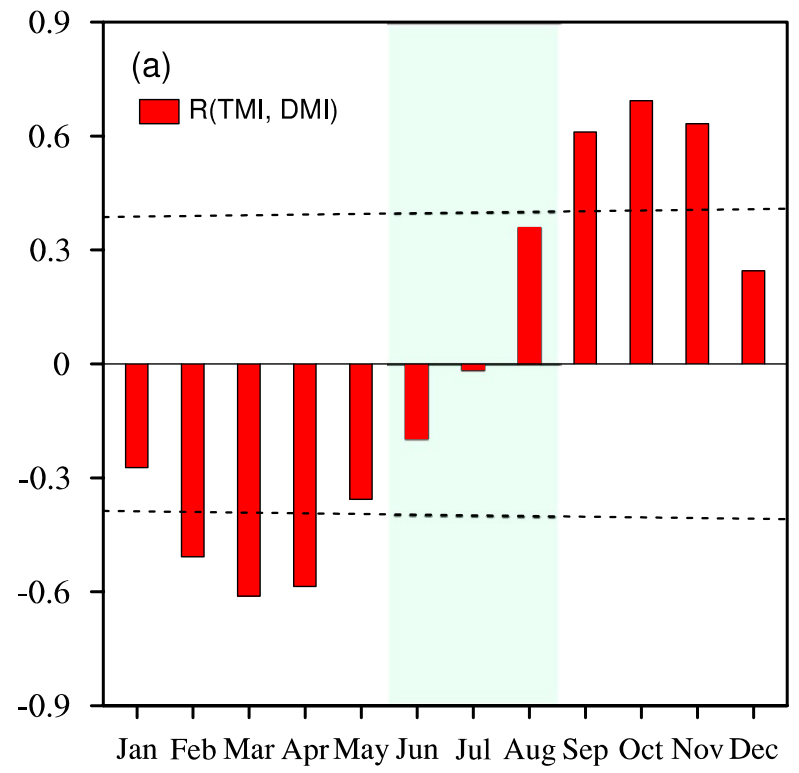

Fig. 6 a Monthly correlations (red bars) between the TMI and DMI during 1982-2017. b Correlations of the TMI (orange bars) and DMI (light blue bars) with the area-averaged SSTAs over the southeastern $\left([\mathrm{SSTAs}]_{\mathrm{E}}\right)$, central $\left([\mathrm{SSTAs}]_{\mathrm{C}}\right)$, and western $\left([\mathrm{SSTAs}]_{\mathrm{W}}\right)$ Indian Ocean during JJA, as shown in Eq. (3). Notably, the correlations

IOD may result from the IOBM signals that peak in this period (Fig. 6a). When the IOT peaks during JJA, although the IOD begins to develop in this period, the IOT is not significantly correlated with the IOD. However, as the IOT weakens during SON, the correlations between the IOT and IOD become significant again (Fig. 6a). These results indicate a weak relationship between the IOT and IOD during JJA, which can also be supported by the correlations of the TMI (DMI) with the SSTAs over the southeastern $\left([\text { SSTAs }]_{\mathrm{E}}\right)$, central $\left([\mathrm{SSTAs}]_{\mathrm{C}}\right)$ and western $\left([\mathrm{SSTAs}]_{\mathrm{W}}\right)$ Indian Ocean during JJA (Fig. 6b).

The correlation between the TMI and [SSTAs $]_{\mathrm{E}}$ is significantly negative with a value of -0.65 in JJA, although it is weaker than the correlation between the DMI and $[\text { SSTAs }]_{\mathrm{E}}(-0.75$, Fig. 6b). The SSTAs over the central Indian Ocean are significantly correlated with the TMI during JJA, but with an insignificant correlation $(-0.01)$ with the DMI, implying that the SSTAs over the central Indian Ocean play a more important role in IOT evolution than in IOD evolution during JJA. Moreover, the correlation coefficient between the TMI and [SSTAs $]_{\mathrm{C}}$ is 0.65 , even larger than that between the TMI and the [SSTAs $]_{\mathrm{E}}$ (Fig. 6b). This indicates that the SSTAs over the central and southeastern Indian Ocean are both equally important for IOT evolution. Notable differences between the IOT and the IOD also exist over the western Indian Ocean. Although the correlations of the $[\text { SSTAs }]_{\mathrm{W}}$ with the TMI and DMI are both significant during JJA, the SSTAs over the western Indian Ocean are

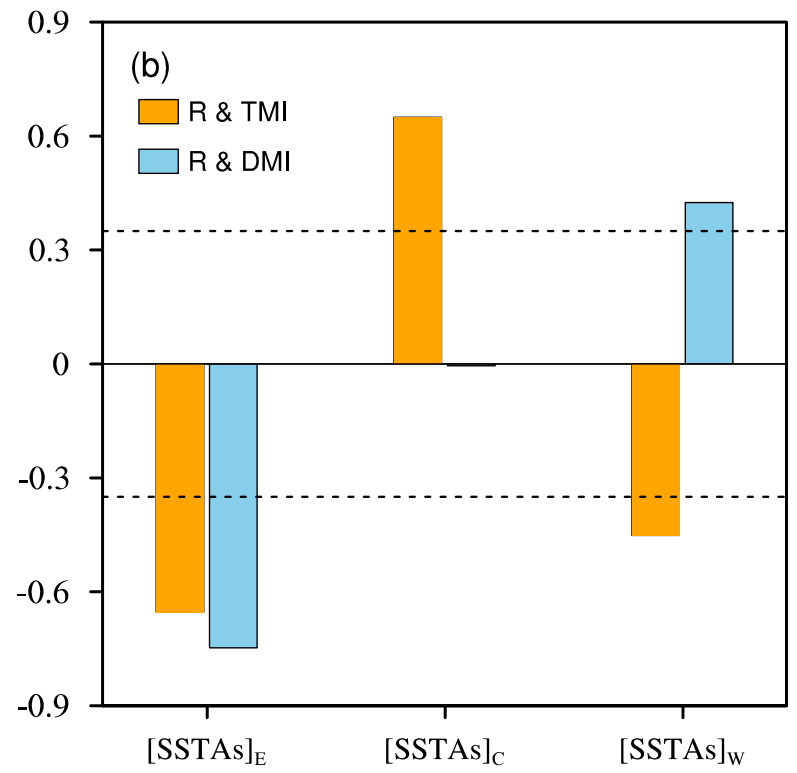

related to the TMI have removed the EOF2 signals. The green shading in a represents the period from June to August, the peak season of the IOT. The dashed lines in $\mathbf{a}, \mathbf{b}$ denote the $99 \%$ confidence level, which is tested by a two-tailed Student's $t$ test using the effective number of degrees of freedom

negatively correlated with the IOT, which is opposite to the correlation with IOD (Fig. 6b). This suggests the contrasting evolution of the SSTAs over the western Indian Ocean between the IOT and IOD events. The above results further demonstrate that the IOT is clearly different from the IOD.

\section{Atmospheric and oceanic processes related to the IOT}

Atmospheric and oceanic processes are known to play an important role in the formation of IOT events. To examine the relative contributions of the net heat flux and each ocean advection term to the IOT, we calculate the heat budget shown in Eq. (1). Equation (1) shows that the anomalous temperature tendency $\left(\partial T^{\prime} / \partial t\right)$ is mainly determined by the net heat flux $\left(Q^{\prime}\right)$ and the anomalous total ocean advection, which comprises the anomalous advection by the zonal current (total zonal advection), by the meridional current (total meridional advection), and the vertical current (total vertical advection).

\subsection{Heat budget diagnosis}

Figure 7a displays composites of the monthly evolution of the anomalous temperature tendency $\left(\partial T^{\prime} / \partial t\right)$, total ocean advection, total zonal advection, total meridional advection, total vertical advection, and net anomalous heat flux $\left(Q^{\prime}\right)$ 
(a) Eastern Indian Ocean

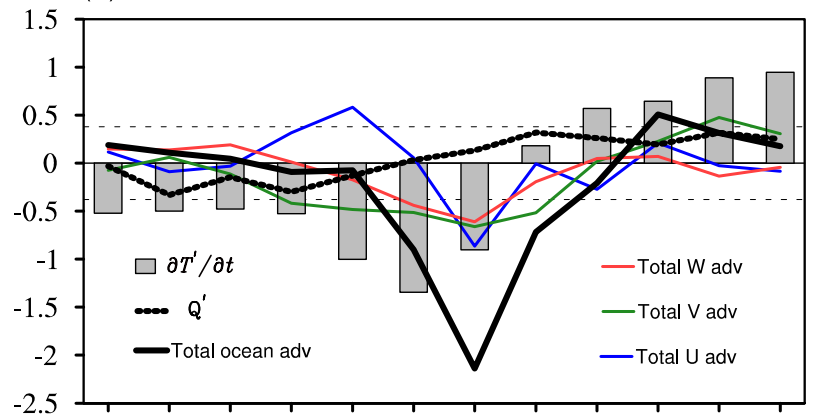

Jan Feb Mar Apr May Jun Jul Aug Sep Oct Nov Dec (b) Central Indian Ocean

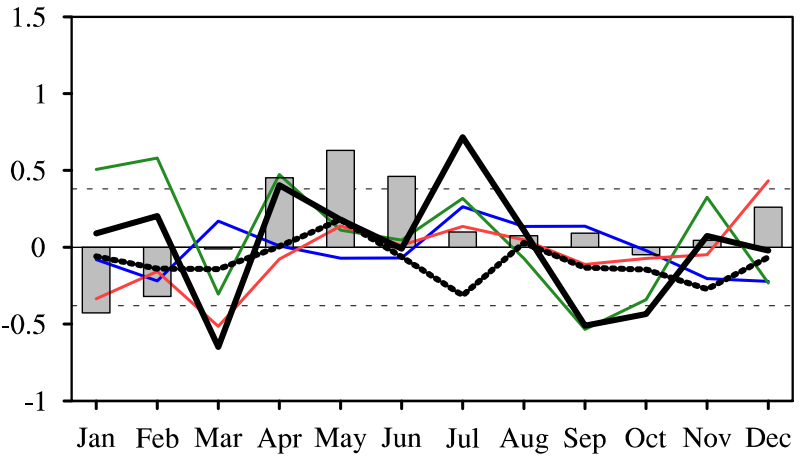

(c) Western Indian Ocean

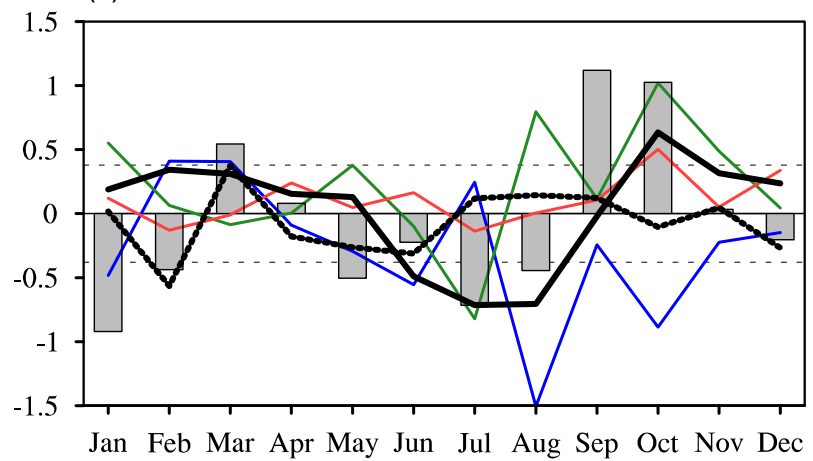

Fig. 7 Composite monthly evolution of the anomalous temperature tendency $\left(\partial T^{\prime} / \partial t\right.$; bars, ${ }^{\circ} \mathrm{C}$ month $\left.{ }^{-1}\right)$, the net heat flux $\left(Q^{\prime}\right.$, black dashed lines, ${ }^{\circ} \mathrm{C}$ month ${ }^{-1}$ ), the total ocean advection (black solid line, ${ }^{\circ} \mathrm{C} \mathrm{mon}^{-1}$ ), the total zonal (blue lines, ${ }^{\circ} \mathrm{C} \mathrm{mon}^{-1}$ ), meridional (green lines, ${ }^{\circ} \mathrm{C} \mathrm{mon}^{-1}$ ), and vertical (red line, ${ }^{\circ} \mathrm{C} \mathrm{mon}{ }^{-1}$ ) advection over the a southeastern $\left(90^{\circ}-110^{\circ} \mathrm{E}, 10^{\circ} \mathrm{S}-0^{\circ}\right)$, b central $\left(65^{\circ}-85^{\circ} \mathrm{E}, 5^{\circ}-20^{\circ}\right.$ $\mathrm{S})$, and $\mathbf{c}$ western $\left(45^{\circ}-60^{\circ} \mathrm{E}, 5^{\circ} \mathrm{S}-20^{\circ} \mathrm{N}\right.$ and $60^{\circ}-70^{\circ} \mathrm{E}, 10^{\circ}-20^{\circ}$ $\mathrm{N})$ Indian Ocean. Note that the oceanic terms are integrated from 0 to 40-m depth. Dashed lines denote $1(-1)$ standard deviation

over the southeastern Indian Ocean. A significant anomalous temperature tendency $\left(\partial T^{\prime} / \partial t\right)$ over the southeastern, central, and western Indian Ocean generally has a peak negative phase in May, June, and July, leading the actual SSTAs by about 2-3 months (Fig. 7a). This indicates that the actual SSTAs are the continuous and cumulative results of the anomalous temperature tendency, which represents the trend (a) Eastern Indian Ocean

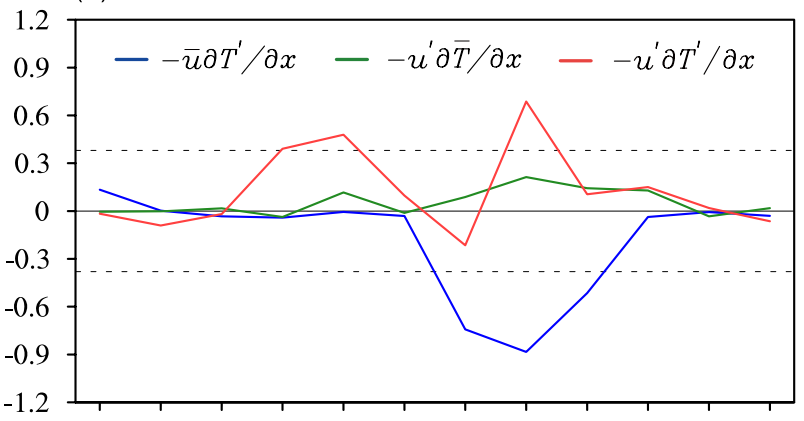

Jan Feb Mar Apr May Jun Jul Aug Sep Oct Nov Dec

(b) Central Indian Ocean

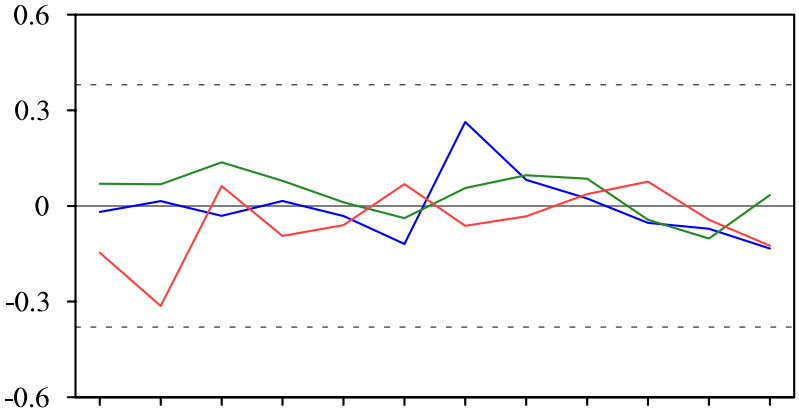

Jan Feb Mar Apr May Jun Jul Aug Sep Oct Nov Dec (c) Western Indian Ocean

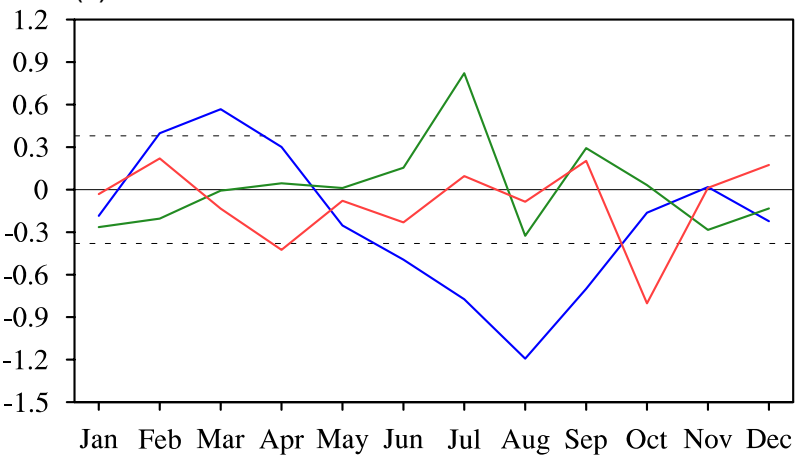

Fig. 8 Same as Fig. 7, but for the advection of the anomalous temperature by the mean zonal current $\left(-\bar{u} \partial T^{\prime} / \partial x\right.$; blue lines, ${ }^{\circ} \mathrm{C}$ month $\left.^{-1}\right)$, the advection of the mean temperature by the anomalous zonal current $\left(-u^{\prime} \partial \bar{T} / \partial x\right.$; green lines, ${ }^{\circ} \mathrm{C}$ month $\left.^{-1}\right)$ and the nonlinear advection of the anomalous temperature by the anomalous zonal current $\left(-u^{\prime} \partial T^{\prime} / \partial x\right.$; red lines, ${ }^{\circ} \mathrm{C}$ month $\left.^{-1}\right)$

of the SSTAs. Although the anomalous total ocean advection that is mainly determined by the anomalous total meridional advection is favorable for the anomalous temperature over the southeastern Indian Ocean during the beginning and evolving stages of the IOT events (April-May), it is much smaller than the anomalous thermal forcing $\left(Q^{\prime}\right.$, Fig. 7a). This indicates that the enhancement of the anomalous temperature may be attributed to changes in the net heat flux associated with the atmospheric processes during this period (Fig. 7a). The situation is reversed during the mature stage of 
(a) Eastern Indian Ocean

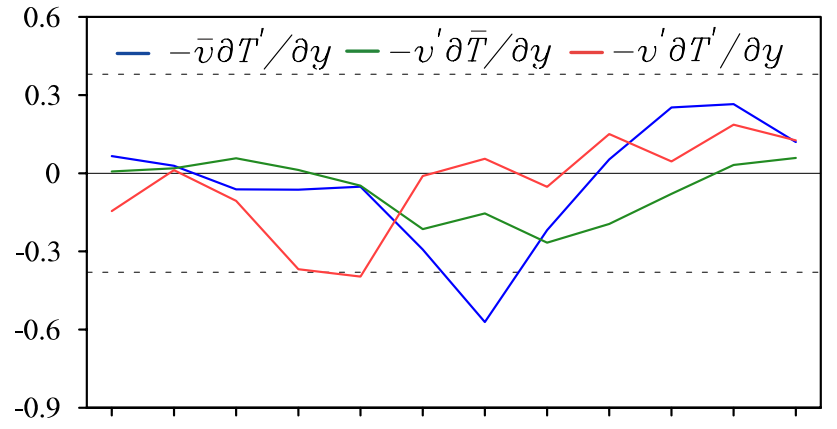

Jan Feb Mar Apr May Jun Jul Aug Sep Oct Nov Dec (b) Central Indian Ocean

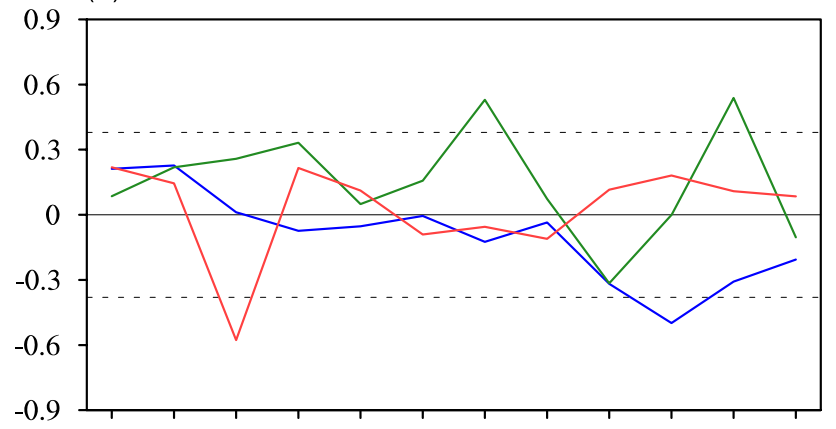

Jan Feb Mar Apr May Jun Jul Aug Sep Oct Nov Dec (c) Western Indian Ocean

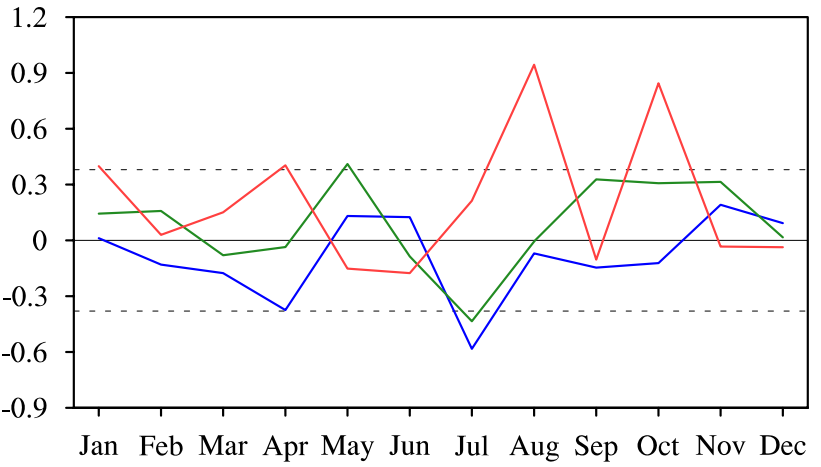

Fig. 9 Same as Fig. 7, but for the advection of the anomalous temperature by the mean meridional current $\left(-\bar{v} \partial T^{\prime} / \partial y\right.$; blue lines, ${ }^{\circ} \mathrm{C}$ month ${ }^{-1}$ ), the advection of the mean temperature by the anomalous meridional current $\left(-v^{\prime} \partial \bar{T} / \partial y\right.$; green lines, ${ }^{\circ} \mathrm{C}$ month $\left.^{-1}\right)$ and the nonlinear advection of the anomalous temperature by the anomalous meridional current $\left(-v^{\prime} \partial T^{\prime} / \partial y\right.$; red lines, ${ }^{\circ} \mathrm{C}$ month $\left.^{-1}\right)$

the IOT events (JJA). The anomalous total ocean advection plays a dominant role in the enhancement of the anomalous temperature, while the anomalous net heat flux acts as the damping term (Fig. 7a). The three terms associated with the ocean currents have the comparable contributions to the anomalous temperature during the peak stage (Fig. 7a), especially in July, suggesting the importance of the ocean currents off Sumatra-Java in the mature stage of the IOT events.
In contrast, over the central Indian Ocean, the anomalous total meridional advection plays a major contributor in the temperature anomaly in April-May, and then is replaced as the dominant term by the anomalous total ocean advection in July (Fig. 7b). However, both anomalous atmosphere and ocean currents are not favorable for the anomalous temperature in June, which may be affected by the residual terms $(R$, Fig. $7 \mathrm{~b})$. In the western Indian Ocean, the temperature anomaly is largely determined by the anomalous net heat flux and partly contributed by the anomalous total ocean advection in April-May (Fig. 7c). As the anomalous net heat flux weakens rapidly and indeed damps the anomalous temperature in JJA, the anomalous total ocean advection becomes the major contributor (Fig. 7c). The anomalous zonal advection plays the dominant role in the anomalous total ocean advection in June and August over the western Indian Ocean, while the anomalous total meridional and vertical advections dominate in July (Fig. 7c).

\subsection{Contributions of the anomalous advection terms}

As shown in the heat budget Eq. (1), each component of the anomalous total ocean advection is composed of three terms: the anomalous advection of the anomalous temperature by the mean current, the anomalous advection of the mean temperature by the anomalous current, and the nonlinear advection of the anomalous temperature by the anomalous current.

\subsubsection{Anomalous zonal advection}

Figure 8 shows the composites of each component of anomalous total zonal advection over the southeastern, central, and western Indian Ocean. The anomalous advection of the anomalous temperature by the mean zonal current $\left(-\bar{u} \partial T^{\prime} / \partial x\right)$ over the southeastern Indian Ocean significantly contributes to the anomalous temperature during the mature period of the IOT events, and is much larger than the contributions of the anomalous advection of the mean temperature by the anomalous zonal current $\left(-u^{\prime} \partial \bar{T} / \partial x\right)$ and the nonlinear advection of the anomalous temperature by the anomalous zonal current $\left(-u^{\prime} \partial T^{\prime} / \partial x\right)$ (Fig. 8a). In the central Indian Ocean, the small contribution of the anomalous total zonal advection to the anomalous temperature tendency is due to offsetting of the three components of anomalous zonal advection, including $-u^{\prime} \partial \bar{T} / \partial x,-\bar{u} \partial T^{\prime} / \partial x$, and $-u^{\prime} \partial T^{\prime} / \partial x$ (Fig. 8b).

In contrast to the anomalous advection of the mean temperature by the anomalous zonal current $\left(-u^{\prime} \partial \bar{T} / \partial x\right)$ and the nonlinear advection of the anomalous temperature by the anomalous zonal current $\left(-u^{\prime} \partial T^{\prime} / \partial x\right)$, the anomalous 
(a) Eastern Indian Ocean

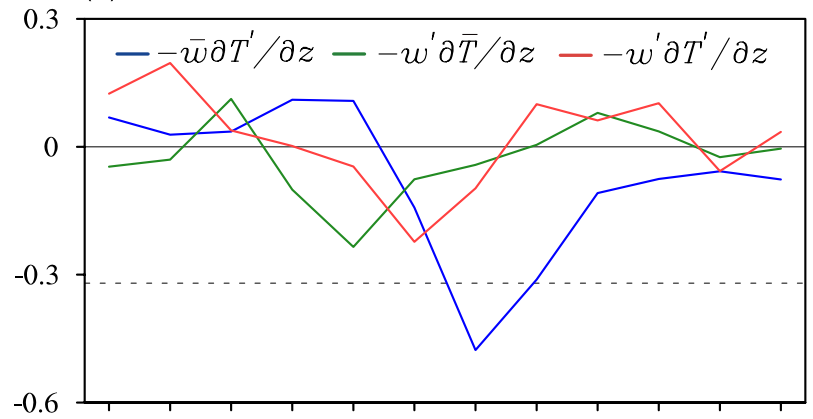

Jan Feb Mar Apr May Jun Jul Aug Sep Oct Nov Dec (b) Central Indian Ocean

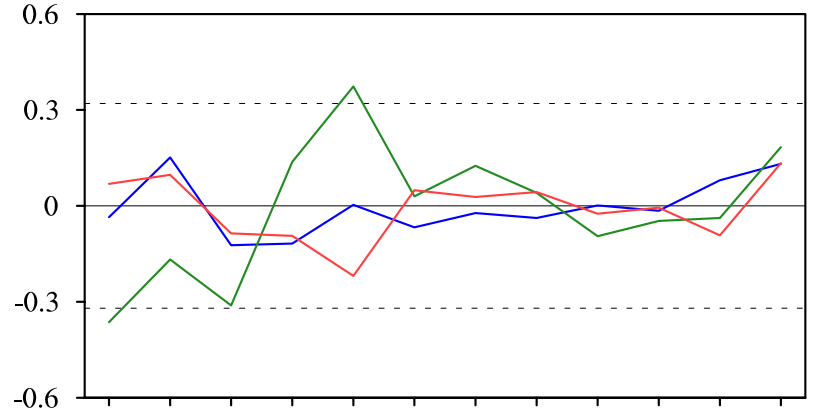

Jan Feb Mar Apr May Jun Jul Aug Sep Oct Nov Dec (c) Western Indian Ocean

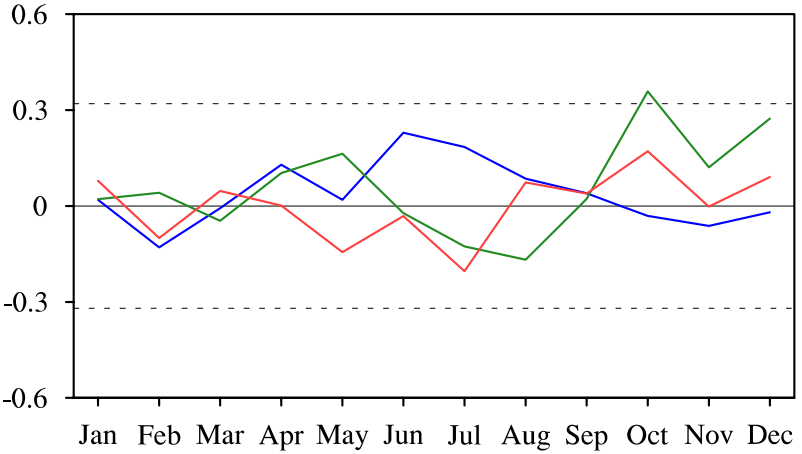

Fig. 10 Same as Fig. 7, but for the advection of the mean temperature by the anomalous upwelling $\left(-w^{\prime} \partial \bar{T} / \partial z\right.$; blue lines, ${ }^{\circ} \mathrm{C}$ month $\left.{ }^{-1}\right)$, the advection of the anomalous temperature by the mean upwelling $\left(-\bar{w} \partial T^{\prime} / \partial z\right.$; green lines, ${ }^{\circ} \mathrm{C}$ month $\left.{ }^{-1}\right)$ and the nonlinear advection of the anomalous temperature by the anomalous upwelling $\left(-w^{\prime} \partial T^{\prime} / \partial z\right.$; red lines, ${ }^{\circ} \mathrm{C}$ month $^{-1}$ )

temperature over the western Indian Ocean is largely contributed by the anomalous advection of the anomalous temperature by the mean zonal current $\left(-\bar{u} \partial T^{\prime} / \partial x\right)$ in JJA (Fig. 8c).

\subsubsection{Anomalous meridional advection}

Similar to the anomalous total zonal current, the composites of each component of the total meridional current are shown in Fig. 9. Compared to the anomalous advection of the anomalous temperature by the mean meridional current $\left(-\bar{v} \partial T^{\prime} / \partial y\right)$ and of the mean temperature by the anomalous meridional current $\left(-v^{\prime} \partial \bar{T} / \partial y\right)$, the nonlinear advection of the anomalous temperature by the anomalous meridional current $\left(-v^{\prime} \partial T^{\prime} / \partial y\right)$ has the bigger contributions to anomalous temperature in April-May over the southeastern Indian Ocean (Fig. 9a), resulting in the positive contribution of the anomalous total meridional advection to the anomalous temperature tendency (Fig. 7a). The positive contribution of the anomalous total meridional advection to the anomalous temperature is largely contributed by the anomalous advection of the anomalous temperature by the mean meridional current $\left(-\bar{v} \partial T^{\prime} / \partial y\right)$ in June-August (Fig. 9a).

Over the central Indian Ocean, the advection of the mean temperature by the anomalous meridional current $\left(-v^{\prime} \partial \bar{T} / \partial y\right)$ and the advection of anomalous temperature by the anomalous meridional current $\left(-v^{\prime} \partial T^{\prime} / \partial y\right)$ are much stronger than the anomalous advection of the anomalous temperature by the mean meridional current $\left(-\bar{v} \partial T^{\prime} / \partial y\right)$ (Fig. 9b), leading to the positive contribution of the anomalous total meridional advection to the anomalous temperature trend in April-May (Fig. 7b). The contribution of the anomalous total meridional advection over the central Indian Ocean becomes negative in June (Fig. 7b), which is caused by negative contributions of the advection associated with the anomalous meridional current in this period (Fig. 9b). In July, the anomalous temperature is mainly determined by the mean temperature by the anomalous meridional current $\left(-v^{\prime} \partial \bar{T} / \partial y\right)$ (Fig. 9b).

In the western Indian Ocean, the nonlinear advection of the anomalous temperature by the meridional current $\left(-v^{\prime} \partial T^{\prime} / \partial y\right)$ is strongly counteracted by the advection of the anomalous temperature by the mean meridional current $\left(-\bar{v} \partial T^{\prime} / \partial y\right)$ and of the mean temperature by the anomalous meridional current $\left(-v^{\prime} \partial \bar{T} / \partial y\right)$ in May-June (Fig. 8c), which leads to the slight negative contribution of the anomalous total meridional advection to the anomalous temperature (Fig. 7c). The nonlinear advection of the anomalous temperature by the meridional current $\left(-v^{\prime} \partial T^{\prime} / \partial y\right)$ intensifies significantly in July, but much weaker than the advection of the anomalous temperature by the mean meridional current $\left(-\bar{v} \partial T^{\prime} / \partial y\right)$ and of the mean temperature by the anomalous meridional current $\left(-v^{\prime} \partial \bar{T} / \partial y\right.$, Fig. 9c). Thus, the anomalous total meridional advection makes the major positive contribution to the anomalous temperature in July over the southeastern Indian Ocean as shown in Fig. 7c.

\subsubsection{Anomalous vertical advection}

Likewise, we calculate the composite of each component of the anomalous total vertical current (Fig. 10). The slight negative contribution of the anomalous total vertical advection to the anomalous temperature over the southeastern Indian Ocean is due to the opposing effects of the three 
terms associated with the upwelling during April-May (Figs. 7a, 10a). By June-August, the advection of the anomalous temperature by the mean upwelling $\left(-\bar{w} \partial T^{\prime} / \partial z\right)$ and of the anomalous temperature by the anomalous upwelling $\left(-w^{\prime} \partial T^{\prime} / \partial z\right)$ become the two larger contributors to the anomalous temperature over the southeastern Indian Ocean (Figs. 7a, 10a).

In the central Indian Ocean, the advection of the mean temperature by the anomalous upwelling $\left(-w^{\prime} \partial \bar{T} / \partial z\right)$ is largely counteracted by the nonlinear advection of the anomalous temperature by the anomalous upwelling $\left(-w^{\prime} \partial T^{\prime} / \partial z\right)$ in April-May. The three terms associated with the upwelling current become small in June-August, so that the anomalous total upwelling advection contributes little to the anomalous temperature (Fig. 7b). Although the advection of anomalous temperature by anomalous upwelling $\left(-w^{\prime} \partial T^{\prime} / \partial z\right)$ makes a positive contribution to the anomalous temperature over the western Indian Ocean in April-May, the opposing effect of the advection of the mean temperature by the anomalous upwelling $\left(-w^{\prime} \partial \bar{T} / \partial z\right)$ and of the anomalous temperature by the mean upwelling $\left(-\bar{w} \partial T^{\prime} / \partial z\right)$ result in the small contribution of the anomalous upwelling advection to the anomalous temperature in this period (Figs. 7c, 10c). By June-July, two terms associated with the anomalous upwelling are the main contributors to the anomalous temperature over the western Indian Ocean, though the advection of the anomalous temperature by the mean upwelling $\left(-\bar{w} \partial T^{\prime} / \partial z\right)$ plays a damped role in the anomalous temperature (Figs. 7c, 10c).

\subsection{Heat budget diagnosis: summary}

The anomalous temperature over the southeastern Indian Ocean is largely determined by the anomalous net heat flux in April-May and by the total ocean advection during June-August. The advection of the anomalous temperature by the mean current, including $-\bar{u} \partial T^{\prime} / \partial x,-\bar{v} \partial T^{\prime} / \partial y$, and $-\bar{w} \partial T^{\prime} / \partial z$, makes the major contribution to the anomalous advection. The anomalous temperature over the central Indian Ocean is mainly driven by advection of the mean temperature by the anomalous meridional current $\left(-v^{\prime} \partial \bar{T} / \partial y\right)$ in April, and the residual terms $(R)$ becomes the major contribution term in May-June. Similar to the southeastern Indian Ocean, the anomalous temperature over the western Indian Ocean is mainly determined by the anomalous net heat flux in April-May, and by advection of the anomalous temperature by the mean zonal current $\left(-\bar{u} \partial T^{\prime} / \partial x\right)$ in June and advection of the anomalous temperature by the mean meridional current $\left(-\bar{v} \partial T^{\prime} / \partial y\right)$ and of the mean temperature by the anomalous meridional current $\left(-v^{\prime} \partial \bar{T} / \partial y\right)$ in July, while is replaced by advection of the anomalous temperature by the mean zonal current $\left(-\bar{u} \partial T^{\prime} / \partial x\right)$ in August. These results demonstrate that the IOT is determined by both atmospheric and oceanic processes.

\section{Discussion and summary}

The tropical Indian Ocean SSTAs during JJA in 1994 showed a unique tripole pattern very different from the wellknown IOD dipole pattern: the tropical central Indian Ocean was warmer than normal, but it was flanked by colder SSTAs to its east and west; this tripole pattern is similar to the EOF3 of Indian Ocean SSTAs. Furthermore, the variances explained by the EOF2 and EOF3 are well separated. This suggests that the tripole pattern is a mode independent of the IOD, and we name it the IOT. The upper ocean heat budget associated with the IOT are investigated emphatically.

Apart from the spatial structures, there are also remarkable differences in the seasonal evolution of IOT and IOD events. While the IOD has a mature phase in SON, the IOT events generally peak in JJA, with this difference corresponding to the contrasting wind anomalies. In the IOT events, the significant southeasterly anomalies over the southeastern Indian Ocean first appear in April-May, and are much stronger than in the IOD events, thereby reinforcing the colder SSTAs off Sumatra-Java during the IOT events in this period. In JJA, the enhanced southeasterly wind anomalies associated with IOD events propagate westward into the western Indian Ocean along the equator in JJA and then warm the SSTAs there. However, during the IOT events in JJA, the easterly wind anomalies from the southeastern Indian Ocean are counteracted by westerly wind anomalies from the western Indian Ocean in the equatorial central Indian Ocean, enhancing the northerly wind anomalies over the central Indian Ocean to the south of the equator, and further warming the SSTAs over the southern Indian Ocean. Meanwhile, the cold SSTAs induced by the enhanced westerly wind anomalies over the western Indian Ocean, together with the cold SSTAs over the southeastern Indian Ocean and warm SSTAs over the central Indian Ocean, show a prominent tripole pattern, indicating the mature phase of the IOT events. As the easterly and westerly wind anomalies over the southeastern and western Indian Ocean weaken, the significant tripole pattern associated with the IOT events starts to weaken gradually in SON and fades away rapidly in boreal winter. In contrast, in IOD events the increased easterly wind anomalies intensify the cold (warm) SSTAs over the southeastern (western) Indian Ocean in SON, leading to the peak of the IOD events.

Correlation analysis further illustrates the differences between the IOT and IOD events. Firstly, the correlations of the TMI with the PC2 and DMI are 0.06 and 0.2 , respectively, implying the insignificant relationship between them. Secondly, the SSTAs over the southeastern Indian Ocean are significantly correlated with the IOT during JJA, similar to the situation with the IOD. There is significant 
(a) TMI \& Niño3

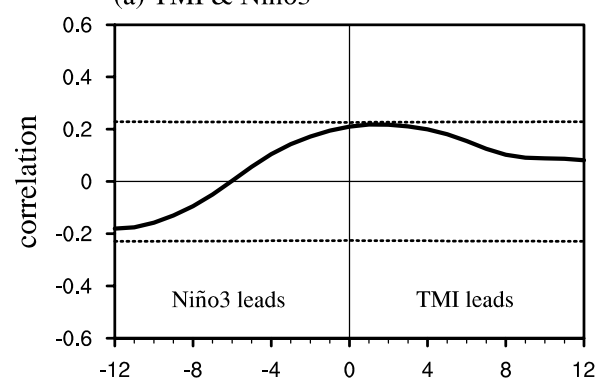

(d) DMI \& Niño3

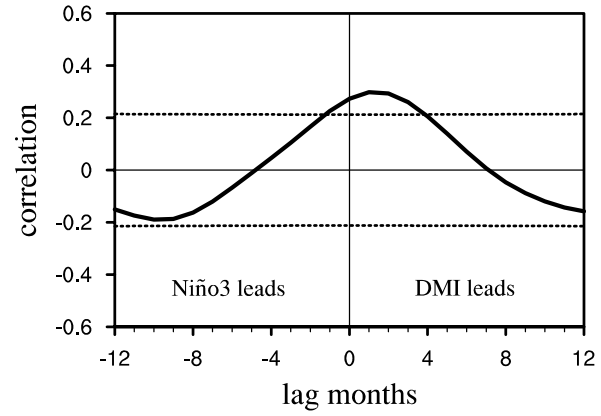

(b) TMI \& EMI

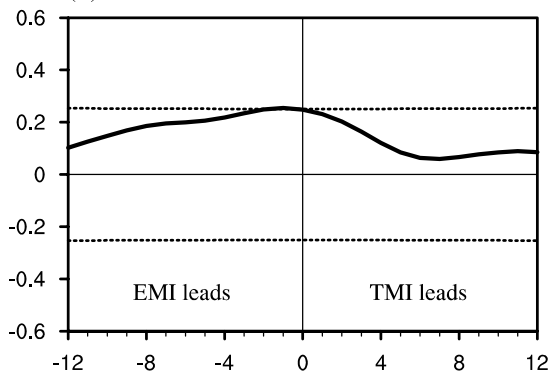

(e) DMI \& EMI

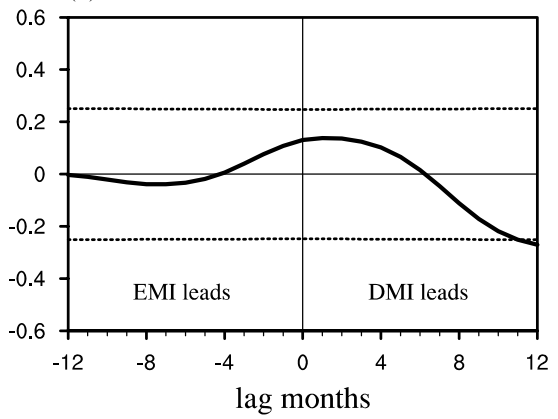

(c) TMI \& SDMI

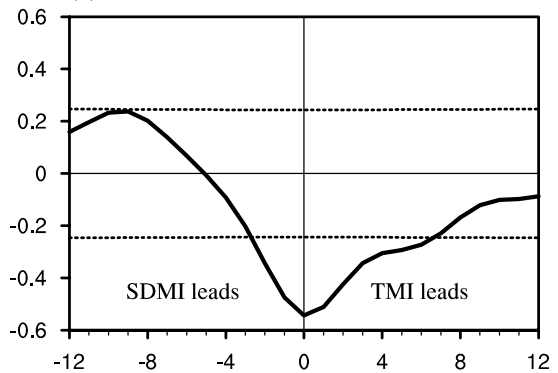

(f) DMI \& SDMI

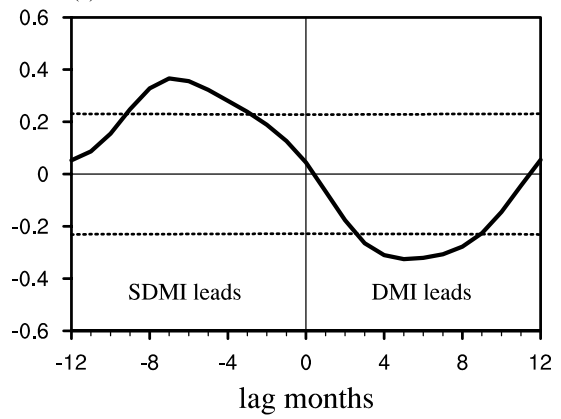

Fig. 11 Lead-lag correlations between pairs of indices. a TMI and Niño3, b TMI and EMI, c TMI and SMDI, d DMI and Niño3, e DMI and EMI, and $\mathbf{f}$ DMI and SDMI. Dashed lines denote the $99 \%$ confi- dence level tested by a two-tailed Student's $t$ test using the effective number of degrees of freedom

anomalous temperature is mainly driven by the advection of the mean temperature by the anomalous meridional current $\left(-v^{\prime} \partial \bar{T} / \partial x\right)$ in April and the residual terms $(R)$ in May-June over the central Indian Ocean, which is replaced by advection of the anomalous temperature by the mean zonal current $\left(-\bar{u} \partial T^{\prime} / \partial x\right)$ in August.

Furthermore, the relationships between the IOD and two types of ENSO have been discussed in many previous studies (e.g., Zhang et al. 2015; Stuecker et al. 2017; Zhang et al. 2019). It is therefore useful to discuss the relationship between the IOT and the two types of ENSO using lead-lag correlation (Fig. 11). In contrast to the insignificant correlations between the TMI and Niño3 index for different lead-lag months, the TMI significantly lags the EMI by 1-2 months (Fig. 11a, b). On the contrary, the DMI significantly leads the Niño3 index by about 2 months, but has an insignificant correlation with EMI (Fig. 11d, e). These results indicate that the IOT is more closely associated with ENSO Modoki, while there is a closer relationship between the IOD and the canonical ENSO. Thus, further discussion of the relationships between the IOT and two types of ENSO is helpful for understanding the interaction between the Indian and Pacific Oceans.

We further calculate the lead-lag correlations of the SDMI with the TMI and DMI. In general, the SDM peaks during boreal winter (Behera and Yamagata 2001; Reason 2001), whereas the TMI has a significant simultaneous correlation with the SDMI (Fig. 11c). When the IOT coexists e anomalous meridional current $\left(-v^{\prime} \partial \bar{T} / \partial y\right)$ plays dominant role over the western Indian Ocean. In contrast, the 
with the SDM, there exists a most significant negative correlation as the former leads the latter by about 2-3 months (not shown). These results imply that the significant simultaneous correlation between the IOT and SDM may be contributed by the other years that the IOT does not co-occur with the SDM. Moreover, the significant correlations between the DMI and the SDMI occur when the IOD (SIOD) leads the SIOD (IOD) by about 5 (7) months (Fig. 11f), further implying that the IOT is quite distinct from the IOD. However, these observational results have not been verified in coupled general circulation models. Further work using coupled general circulation models is required to better understand the physical nature of the IOT and its relationship with other sources of climate variability. In addition, the IOT, as a distinct mode in the tropical Indian Ocean, may exert the significant and independent impacts on the global climate variability during JJA, e.g. the surface temperature over the Indo-China Peninsula, the Mei-yu/Baiu/Changma region, the west Siberian Plain, and North America (not shown). The underlying physical mechanism will also be investigated in depth in the future.

Acknowledgements Thanks for the helpful discussions and suggestions from Dr. Yaokun Li and Dr. Jiaqing Xue. This work was jointly sponsored by the National Natural Science Foundation of China (NSFC) Project (41790474; 41530424) and Shandong Natural Science Foundation Project (ZR2019ZD12). We also thank the powerful supporting of the Center for High Performance Computing and System Simulation, Pilot National Laboratory for Marine Science and Technology (Qingdao).

Open Access This article is licensed under a Creative Commons Attribution 4.0 International License, which permits use, sharing, adaptation, distribution and reproduction in any medium or format, as long as you give appropriate credit to the original author(s) and the source, provide a link to the Creative Commons licence, and indicate if changes were made. The images or other third party material in this article are included in the article's Creative Commons licence, unless indicated otherwise in a credit line to the material. If material is not included in the article's Creative Commons licence and your intended use is not permitted by statutory regulation or exceeds the permitted use, you will need to obtain permission directly from the copyright holder. To view a copy of this licence, visit http://creativecommons.org/licenses/by/4.0/.

\section{References}

Annamalai HR, Murtugudde R, Potemra J, Xie SP, Liu P, Wang B (2003) Coupled dynamics over the Indian Ocean: spring initiation of the zonal mode. Deep Sea Res Part II 50:2305-2330. https:// doi.org/10.1016/S0967-0645(03)00058-4

Ashok K, Guan ZY, Yamagata T (2001) Impact of the Indian Ocean dipole on the relationship between the Indian monsoon rainfall and ENSO. Geophys Res Lett 28:4499-4502. https://doi. org/10.1029/2001gl013294

Ashok K, Behera SK, Rao SA, Weng H, Yamagata T (2007) El Niño Modoki and its possible teleconnection. J Geophys Res 112:C11007. https://doi.org/10.1029/2006JC003798
Behera SK, Yamagata T (2001) Sutropical SST dipole events in the southern Indian Ocean. Geophys Res Lett 28:327-330

Bretherton CS, Widmann M, Dymnidov VP, Wallace JM, Blade I (1999) The effective number of spatial degrees of freedom of a time-varying geld. J Clim 12:1990-2009

Cai W, Cowan T, Sullivan A (2009) Recent unprecedented skewness towards positive Indian Ocean Dipole occurrences and its impact on Australian rainfall. Geophys Res Lett. https://doi. org/10.1029/2009GL037604

Carton JA, Giese BS (2008) A reanalysis of ocean climate using Simple Ocean Data Assimilation (SODA). Mon Weather Rev 136:2999-3017

Ding RQ, Ha KJ, Li JP (2010) Interdecadal shift in the relationship between the East Asian summer monsoon and the tropical Indian Ocean. Clim Dyn 34:1059-1071

Drbohlav HK, Gualdi S, Navarra A (2007) A diagnostic study of the Indian Ocean dipole mode in El Niño and non-El Niño years. J Clim 20:2961-2977. https://doi.org/10.1175/JCLI4153.1

Du Y, Cai WJ, Wu Y (2013) A new type of the Indian Ocean Dipole since the mid-1970s. J Clim 26:959-972

Endo S, Tozuka T (2016) Two flavors of the Indian Ocean dipole. Clim Dyn 46:3371-3385

Fischer AS, Terray P, Guilyardi E, Gualdi S, Delecluse P (2005) Two independent triggers for the Indian Ocean dipole/zonal mode in a coupled GCM. J Clim 18:3428-3449. https://doi.org/10.1175/ JCLI3478.1

Guan ZY, Yamagata T (2003) The unusual summer of 1994 in East Asia: IOD teleconnections. Geophys Res Lett 30:51.51-51.54. https://doi.org/10.1029/2002GL016831

Hong CC, Lu MM, Kanamitsu M (2008) Temporal and spatial characteristics of positive and negative Indian Ocean dipole with and without ENSO. J Geophys Res. https://doi.org/10.1029/2007J D009151

Huang BH, Shukla J (2007a) Mechanisms for the interannual variability in the tropical Indian Ocean. Part I: the role of remote forcing from the tropical Pacific. J Clim 20(13):2917-2936

Huang BH, Shukla J (2007b) Mechanisms for the interannual variability in the tropical Indian Ocean. Part II: regional processes. J Clim 20(13):2937-2960

Huang BY, Thorne PW, Banzon VF, Boyer T, Zhang HM (2017) Extended reconstructed sea surface temperature, version 5 (ersstv5): upgrades, validations, and intercomparisons. J Clim 30:8179-8205. https://doi.org/10.1175/JCLI-D-16-0836.1

Kanamitsu M, Ebisuzaki W, Woollen J, Yang S, Hnilo J, Fiorino M, Potter G (2002) NCEP-DOE AMIP-II reanalysis (R-2). Bull Am Meteorol Soc 83:1631-1643. https://doi.org/10.1175/BAMS-8311-16311982-2018

Kara AB, Rochford PA, Hurlburt HE (2003) Mixed layer depth variability over the global ocean. J Geophys Res 108(C3):3079. https ://doi.org/10.1029/2000JC000736

Krishnan R, Swapna P (2009) Significant influence of the boreal summer monsoon flow on the Indian Ocean response during dipole events. J Clim 22:5611-5634. https://doi.org/10.1175/2009jcli21 76.1

Kug JS, Kang IS, Lee JY, Jhun JG (2004) A statistical approach to Indian Ocean sea surface temperature prediction using a dynamical ENSO prediction. Geophys Res Lett. https://doi. org/10.1029/2003g1019209

Kug JS, Jin FF, An SI (2009) Two types of El Niño events: cold tongue El Niño and warm pool El Niño. J Clim 22:1499-1515

Lau NC, Nath MJ (2004) Coupled GCM simulation of atmosphere-ocean variability associated with zonally asymmetric SST changes in the tropical Indian Ocean. J Clim 17:245-265. https://doi.org/10.1175/1520-0442(2004)017\%3c0245:CGSOA $\mathrm{V} \% 3 \mathrm{e} 2.0 . \mathrm{CO} ; 2$ 
Li CY, Mu M (2001) The influence of the Indian Ocean dipole on atmospheric circulation and climate. Adv Atmos Sci 18:831-843

Li JP, Wu GX, Hu DX (2011a) Ocean-atmosphere interaction over the joining area of Asia and Indian-Pacific Ocean and its impact on the short-term climate variation in China (in Chinese), vol 1. China Meteorological Press, Beijing, p 516

Li JP, Wu GX, Hu DX (2011b) Ocean-Atmosphere interaction over the joining area of Asia and Indian-Pacific Ocean and its impact on the short-term climate variation in China (in Chinese), vol 2. China Meteorological Press, Beijing, p 565

Li JP, Sun C, Jin FF (2013) NAO implicated as a predictor of Northern Hemisphere mean temperature multi-decadal variability. Geophys Res Lett 40:5497-5502

Li Y, Li JP, Zhang W, Zhao X, Xie F, Zheng F (2015) Ocean dynamical processes associated with the tropical Pacific cold tongue mode. J Geophys Res 120:6419-6435. https://doi.org/10.1002/2015J $\mathrm{C} 010814$

Luo JJ, Masson S, Behera S, Yamagata T (2007) Experimental forecasts of the Indian Ocean dipole using a coupled OAGCM. J Clim 20:2178-2190

Luo JJ, Behera S, Masumoto Y, Sakuma H, Yamagata T (2008) Successful prediction of the consecutive IOD in 2006 and 2007. Geophys Res Lett. https://doi.org/10.1029/2007GL032793

Murtugudde R, McCreary JP Jr, Busalacchi AJ (2000) Oceanic processes associated with anomalous events in the Indian Ocean with relevance to 1997-1998. J Geophys Res 105:3295-3306

North GR, Bell TL, Chalan RF (1982) Sampling errors in the estimation of empirical orthogonal functions. Mon Weather Rev 110:699-706

Nuncio M, Yuan X (2015) The influence of the Indian Ocean dipole on Antarctic sea ice. J Clim 28:2682-2690. https://doi.org/10.1175/ JCLI-D-14-00390.1

Rao SA, Yamagata T (2004) Abrupt termination of Indian Ocean dipole events in response to intra-seasonal disturbances. Geophys Res Lett. https://doi.org/10.1029/2004GL020842

Rao SA, Luo JJ, Behera SK, Yamagata T (2009) Generation and termination of Indian Ocean dipole events in 2003, 2006 and 2007. Clim Dyn 33:751-767

Rayner N, Parker DE, Horton E, Folland C, Alexander L, Rowell D, Kent E, Kaplan A (2003) Global analyses of sea surface temperature, sea ice, and night marine air temperature since the late nineteenth century. J Atmos Sci. https://doi.org/10.1029/2002J D002670

Reason CJC (2001) Subtropical Indian Ocean SST dipole events and southern African rainfall. Geophys Res Lett 28:2225-2228

Ren HL, Jin FF (2013) Recharge oscillator mechanisms in two types of ENSO. J Clim 26:6506-6523

Reynolds RW, Rayner NA, Smith TM, Stokes DC, Wang W (2002) An improved in situ and satellite SST analysis for climate. J Clim 15:1609-1625

Saji NH, Yamagata T (2003) Structure of SST and surface wind variability during Indian Ocean dipole mode events: COADS observations. J Clim 16:2735-2751. https://doi.org/10.1175/15200442(2003)016,2735:sosasw.2.0.co;2

Saji NH, Goswami BN, Vinayachandran PN, Yamagata T (1999) A dipole mode in the tropical Indian Ocean. Nature 401:360-363. https://doi.org/10.1038/43854
Schott FA, Xie SP, McCreary JP (2009) Indian Ocean circulation and climate variability. Rev Geophys. https://doi.org/10.1029/2007R G000245

Shi L, Hendon HH, Alves O, Luo JJ, Balmaseda M, Anderson D (2011) How predictable is the Indian Ocean dipole? Mon Weather Rev 140:3867-3884

Song Q, Vecchi GA, Rosati AJ (2007) Indian Ocean variability in the GFDL coupled climate model. J. Clim 20:2895-2916. https ://doi.org/10.1175/JCLI4159.1

Stuecker MF, Timmermann A, Jin FF, Chikamoto Y, Zhang W, Wittenberg AT, Widiasih E, Zhao S (2017) Revisiting ENSO/Indian Ocean dipole phase relationships. Geophys Res Lett 44:24812492. https://doi.org/10.1002/2016GL072308

Sun S, Lan J, Fang Y, Tana Gao X (2015) A triggering mechanism for the Indian Ocean dipoles independent of ENSO. J Clim 28:5063-5076

Tozuka T, Luo JJ, Masson S, Yamagata T (2007) Decadal modulations of the Indian Ocean dipole in the SINTEX-F1 coupled GCM. J Clim 20:2881-2894. https://doi.org/10.1175/JCLI4 168.1

Tozuka T, Endo S, Yamagata T (2016) Anomalous walker circulations associated with two flavors of the Indian Ocean dipole. Geophys Res Lett 44:5378-5384

Wang YH, Li JP, Zhang YZ, Wang QY, Qin JH (2019) Atmospheric energetics over the tropical Indian Ocean during Indian Ocean dipole events. Clim Dyn 52:6243-6256. https://doi.org/10.1007/ s00382-018-4510-y

Webster PJ, Moore AM, Loschnigg JP, Leben RR (1999) Coupled ocean-atmosphere dynamics in the Indian Ocean during 1997-98. Nature 401:356-360

Yu L, Jin X, Weller RA (2008) Multidecade Global Flux Datasets from the Objectively Analyzed Air-sea Fluxes (OAFlux) Project: Latent and sensible heat fluxes, ocean evaporation, and related surface meteorological variables. OA-2008-1, Woods Hole Oceanographic Institution, p 64

Yuan Y, Yang H, Zhou W, Li C (2008) Influences of the Indian Ocean dipole on the Asian summer monsoon in the following year. Int $\mathrm{J}$ Climatol 28:1849-1859. https://doi.org/10.1002/joc.1678

Zhang WJ, Wang Y, Jin FF, Stuecker MF, Turner AG (2015) Impact of different El Niño types on the El Niño/IOD relationship. Geophys Res Lett 42:8570-8576

Zhang YZ, Li JP, Xue JQ, Feng J, Wang QY, Xu YD, Wang YH, Zheng $F$ (2018) Impact of the South China sea summer monsoon on the Indian Ocean dipole. J Clim 31:6557-6573

Zhang YZ, Li JP, Xue JQ, Zheng F, Wu RG, Ha KJ, Feng J (2019) The relative roles of the South China Sea summer monsoon and ENSO in the Indian Ocean dipole development. Clim Dyn 53:6665-6680. https://doi.org/10.1007/s00382-019-04953-4

Zhao S, Jin FF, Stuecker MF (2019) Improved predictability of the Indian Ocean Dipole using seasonally modulated ENSO forcing forecasts. Geophys Res Lett 46:9980-9990. https://doi. org/10.1029/2019g1084196

Publisher's Note Springer Nature remains neutral with regard to jurisdictional claims in published maps and institutional affiliations. 